Document de Recherche du Laboratoire d'Économie d'Orléans

DR LEO 2016-09

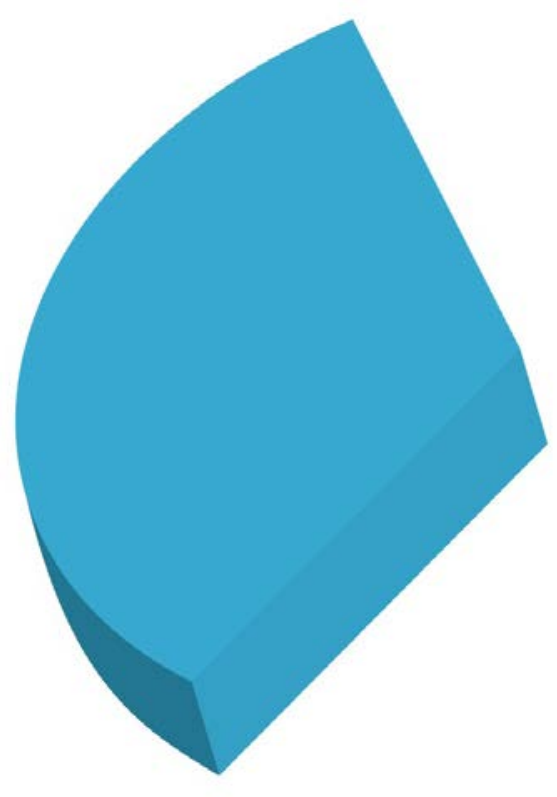

Is a Long War Desirable? Optimal Debt Concessions

In Attrition Warfare

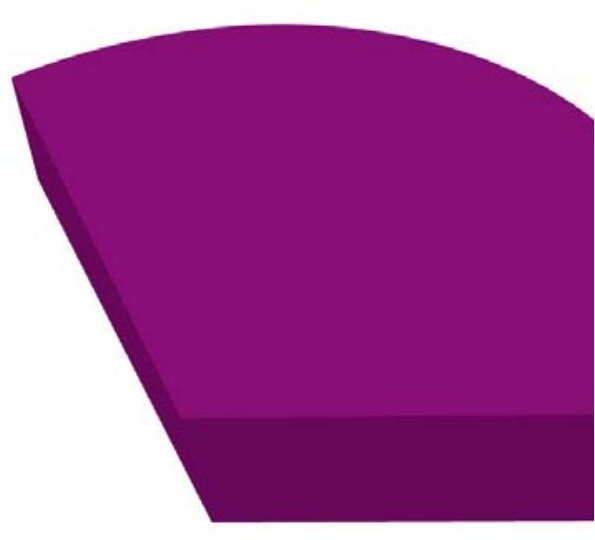

Maxime MENUET 


\title{
Is a Long War Desirable? Optimal Debt Concessions in Attrition Warfare
}

\author{
Maxime Menuet* \\ Univ Orléans, CNRS, LEO, UMR 7322, F-45067, Orléans, France
}

\begin{abstract}
Wars of attrition are often characterized by negotiations and concessions occurring in conflicts, such as peace attempts or ceasefires. The present paper introduces a round of concessions into standard war of attrition models and focuses on a debt stabilization game. Concessions granted by each player in the pre-stabilization period are modeled as an agreement to pay additional taxes with the aim of reducing government deficits and public debt. We compute the symmetric Bayesian-Nash equilibrium and show that concessions prolong the attrition warfare rather than quickly generating a peace period. Thus, concession forms a strategic variable for every player to control and delay the end of the war. Furthermore, we establish that the war-ending outcome, namely debt stabilization, is more delayed under a coalition government than under a single-party government. Finally, this paper contributes to explain failures of austerity measures in public debt stabilization.
\end{abstract}

Keywords: War of attrition, Stabilization delay, Concession, Non-cooperative Game

\section{Introduction}

A war of attrition arises when two (or more) players fight with one another, each one losing welfare but hoping that their opponents will eventually concede. In this way, wars of attrition describe contests characterized by waiting and explain many interaction games. The first models in this vein were developed using a biological framework for struggles over resources ${ }^{1}$ and were used to study armed conflicts. Indeed, military strategists often contrast wars of attrition with wars of movement, in which belligerents attempt to achieve rapid victories by maneuvers or concentrations of forces. Canonical historical examples of wars of attrition include the static battles during World War I, through defensive positions in trenches, and the Six Day War (1969-70), chiefly between Egypt and Israel, in which no territory was conquered or surrendered. ${ }^{2}$

\footnotetext{
*maxime.menuet@univ-orleans.fr

${ }^{1}$ See Smith (1974), Riley (1980), or Bliss and Nalebuff (1984).

${ }^{2}$ Many modern wars of attrition are presented by Malkasian (2002). Specifically, attrition battles from World War I have recently been studied by, e.g., Foley (2005) and Philpott (2014).
} 
Regarding economic contexts, negotiations, such as those involving trade unions and management on labor negotiations, political parties in coalition governments, and monetary and budgetary authorities (see, e.g., Backus and Driffill, 1985; Tabellini, 1988), have often been understood as wars of attrition. In addition, regarding industrial organization, many works have contended that entering emerging markets or securing control of new technologies resemble wars of attrition (see Bulow and Kemperer, 1999). Regarding macroeconomic contexts, recent sovereign debt crises, especially in European countries (such as Greece and Italy) can be analyzed through an attrition framework. In their seminal work, Alesina and Drazen (1991) argue that the process leading to a public debt stabilization can be described as a war of attrition among various socioeconomic groups with conflicting distributional objectives.

Those authors develop a model in which delaying debt stabilization results from a distributional conflict among political groups concerning how to distribute the burden from fiscal policy, which requires eliminating budget deficits and curbing the growth of public debt. These groups are willing to wait because the first group that surrenders loses and pays more than half of the fiscal burden. In other words, even if all groups desire debt stabilization, they will nevertheless fight to avoid assuming the largest share of the fiscal burden necessary to realize debt stabilization. In addition, in a incomplete information environment, during the conflict, each group revises its beliefs concerning the opponent's ability to surrender (i.e., to agree to pay the greater fraction of the fiscal burden) first.

However, all attrition models do not include frequent negotiation or concession contexts, which characterizes long attrition conflicts. Indeed, during war, players often have the opportunity to negotiate with their opponents to reduce the war's intensity and the associated loss of welfare. This round of negotiations (or concessions) during war can include partial armistices, ceasefire agreements, attempts for peace in military conflicts, or more generally, negotiations round-tables involving trade unions or members of a government coalition. Following our previous example, many historians have highlighted the peace attempts made during World War I, which began in $1916 .{ }^{3}$ Their main explanation relates to the war weariness due to the war's long duration, which led some belligerents (such as Germany) to seek a partial peace treaty. Regarding the stabilization of public debt, concessions often consist of adopting policies to reduce budget deficits (e.g., austerity measures, including tax increases or structural reforms) to decrease the level of public debt and, in turn, the tax burden, which represents the collective purpose of the war. These concessions were notably adopted in recent debt crises; for example, drastic austerity measures were implemented in Greece and Italy.

The present paper analyzes this issue by introducing a round of concessions into standard war of attrition models. We focus on a debt stabilization game following Alesina and Drazen (1991) and model a concession granted by each players during the prestabilization period as an agreement to pay additional taxes with the aim of reducing government deficits and public debt. In this way, during the concession round, each political group has two strategic variables. ${ }^{4}$ Each player individually and simultaneously determines both his optimal concession and his drop-out time that generates the debt

\footnotetext{
${ }^{3}$ See, e.g., Scherer and Grunewald (1962); Duroselle (2002); Renoton-Beine (2004).

${ }^{4}$ In particular, each player can represent a political party belonging to a same coalition government, and a concession round can be imposed on all groups or parties by an international institution such as
} 
stabilization outcome, according to the opponent's behavior. As a result an unique, symmetric Beysian-Nash equilibrium is obtained that depends on the individual-level random cost of war.

This modification of standard war of attrition models has interesting consequences. Our main result is that concessions prolong the war instead of rapidly leading to a peace period. Therefore, we show that concession forms a strategic variable whereby every player can control and delay the end of the war. Indeed, each player can agree to reduce the intensity of the conflict and, in turn, prolong the war. Specifically, the optimal concession increases in the probability of losing the war of attrition. Intuitively, when a player faces a substantial risk of losing, he attempts to delay the resolution of the conflict by conceding. ${ }^{5}$

The second result is that the war-ending outcome, namely debt stabilization, is more delayed under coalition government than single-party government, which concurs with the famous result of Spolaore (1993). ${ }^{6}$ The intuition is that the higher the political polarization, the greater the inequality in the allocation of the financial burden of stabilization and the more costly defeat will be relative to victory. Consequently, as the war-ending outcome generates a loss of welfare, players are induced to prolong the war by making concessions during the conflict.

Our results contribute to explaining why concessions during wars of attrition (e.g., peace attempts or ceasefires) fail to solve conflicts and generate peace. Indeed, we show that these concessions, on the contrary, are intended to delay the expensive and risky end-of-war period. Following our example, some historians have argued that the peace proposals made during World War I were aimed more at preserving national interests than at ensuring lasting peace among the belligerents. ${ }^{7}$ More similar to our analysis, regarding the recent sovereign debt crises, austerity programmes implemented in certain European countries failed to stabilize debt levels, e.g., in Greece. Indeed, in return for European bailouts (May 2010 and July 2011), major austerity packages were adopted by the large coalition of A. Samaras in November 2012 and January 2013, but the Greek public debt has continued to grow, rising from 105\% of GDP in 2008 to $177 \%$ of GDP at the end of 2014. Similarly, the substantial Italian debt, which was $116 \%$ of GDP in 2011 , led the then-new Prime Minister, M. Monti, to adopt drastic deficit-reduction measures, which failed to stabilize the debt, which was $123 \%$ of GDP a year later. The explanation developed in this paper is that political groups can concede to pay a small additional share of taxes during the growing debt period to delay the very expensive moment of

the European Union (e.g., in the Pact of Stability and Growth setup) or the IMF; a good example here is the Greek debt crisis, where each bailout is contingent on austerity measures. For a global view of the European sovereign debt crisis, see Lane (2012).

${ }^{5}$ Sporting competitions provide clear examples in this respect. For example, it is well known that the higher the stakes of a football match, the more likely both teams will be to "close the game" by adopting a very defensive strategy, which appears as a "concession strategy". This feature can explain low scores or the multiple penalty shootouts that occurred in the finals of the football World Cup (e.g, in 2006 and 2010).

${ }^{6}$ That author shows that a coalition government delays adjustment, while a single-party government reacts "too much" relative to the social welfare equilibrium because each political party would prefer to be avoid raising taxes. In this way, less political cohesion implies greater difficulties in achieving an agreement to allocate the tax burden and, in turn, prolongs the war of attrition.

${ }^{7}$ Specifically, Duroselle (2002) argues that peace attempts are rather bilateral negotiations to preserve the private interests of each government. 
stabilization that requires to pay the totality of the tax burden. In this way, our model helps to explain the failure of austerity programs to stabilize public debt and agrees with Ardagna and Caselli (2014), who argue that the management of the Greek crisis tends "to be more affected by electoral concerns".

This paper is connected to two strands of political economy literature. On the one hand, many works have extended the seminal contribution of Alesina and Drazen (1991) by focusing on wars of attrition in a public finance framework. In particular, Drazen and Grilli (1993) and Guidotti and Vegh (1999) develop a monetary version, while other authors model incomplete information frameworks (see, e.g., Nalebuff and Riley, 1985; Fudenberg and Tirole, 1986; Krishna and Morgan, 1997; Martinelli and Escorza, 2007), among others). More similar to our model and to the implications in political analysis, Spolaore (1993) demonstrates that the debt stabilization is more delayed under a coalition government than a single-party government. This intuition is tested and confirmed by Padovano and Venturi (2001) in the Italian political framework (1948-94). In addition, wars of attrition among international institutions have been modeled by Casella and Eichengreen (1996) and Carré (2000). The latter introduces an exogenous deadline to represent the Maastricht Treaty, beyond which there is a punishment. She argues that the higher the punishment, the higher the probability of stabilization before the deadline. In this respect, the contribution of this paper is to extend the standard model of Alesina and Drazen (1991) by introducing a round of concessions during the allocation conflict.

On the other hand, this paper belongs to an important strand of literature that explores public debt as a commitment or as a strategic variable for politicians (Aghion and Bolton, 1990; Alesina and Tabellini, 1990a; Milesi-Ferretti and Spolaore, 1994; Drazen, 2000, among others). ${ }^{8}$ Indeed, in our setup, each political group can strategically "manipulate" the amount of public debt by paying additional taxes. In this way, the debt becomes the purpose of concessions and will depend on the political polarization in the society, which follows Alesina and Tabellini (1990b), who show that political polarization and frequent government changes should be associated with higher debt.

The remainder of the paper is organized as follows. Section 2 solves the model, Section 3 establishes the symmetric Bayesian-Nash equilibrium and some comparative statics, Section 4 presents the social welfare equilibrium, and finally, Section 5 concludes.

\section{The Model}

Consider an economy with two political (or interest groups) denoted by $D$ and $R$. Each group is populated by a continuum of households (or agents) with measure normalized to unity. In addition, there is a government that provides public expenditures, either by levying taxes or by issuing public debt. Until $t=0$, the government budget is assumed to be balanced, with external debt constant at level $b(0)$. To start the conflict, at $t=0$, a shock reduces available tax revenues; a share $\gamma>0$ of the deficit is covered by distortionary taxation and a share $1-\gamma$ by issuing debt. Thus, public debt $(b(t))$ evolves according to

$$
\dot{b}(t)=(1-\gamma) d(t)
$$

\footnotetext{
${ }^{8}$ Alesina and Perotti (1994) and Alesina and Passalacqua (2015) present a large survey.
} 
and the amount of distortionary tax $(\tau(t))$ is given by

$$
\tau(t)=\gamma d(t),
$$

where the level of the deficit $(d(t))$ is

$$
d(t)=r b(t)+g(t), \forall t \geq 0,
$$

with $r \geq 0$ denoting the constant interest rate.

In addition, for simplicity, throughout the paper we assume that $b(0)=0$ and that public expenditures are constant over time, i.e., $g(t)=g(0)=: g_{0}, \forall t \geq 0$. Thus, by (3) and (1), the explicit forms of the public debt and deficit are

$$
b(t)=\frac{g_{0}}{r}\left[e^{(1-\gamma) r t}-1\right], \text { and } d(t)=g_{0} e^{(1-\gamma) r t}, \forall t \geq 0 .
$$

As usual, debt stabilization consists of increasing taxes sufficiently to prevent further growth in the debt. Thus, at the time when the debt is stabilized, denoted by the date $T \geq 0$, the deficit is totally covered by distortionary taxation, i.e., $\gamma=1, \forall t \geq T$. Consequently, taxes to be levied at the end of the war $(t=T)$ are $\tau(T)=d(T)$.

\subsection{A concessions round}

The key assumption is that a round of concessions between the two groups occurs before the end of the war at the (exogenous) time $t=\tilde{T}$, where $0 \leq \tilde{T}<T$. At this date, each group can accept a reduction in its share of the collective burden of the war to decrease the individual intensity of the conflict. In our public finance model, group- $i$ 's concession corresponds in an agreement to pay an additional share of the distortionary taxation, denoted by $\beta_{i} \in[0,1 / 2]$, with the aim of reducing the public deficit. Specifically, as public expenditures are constant over time, the greater the concession levels, the less the debt issuance. This process is a simultaneous and non-cooperative game. At $t=\tilde{T}$, group- $i$ chooses its action, namely its concession $\beta_{i}$, simultaneous to but without knowledge of the action chosen by the other group. ${ }^{9}$ Therefore, during the concessions round $(t=\tilde{T})$, the deficit level becomes $\left(1-\beta_{R}-\beta_{D}\right) d(\tilde{T})$, where $\beta_{i} d(\tilde{T})$ represents the additional tax assumed by group- $i$.

In addition, the individual concession $\left(\beta_{i}\right)$ will be successful at reducing the stabilization burden with probability $\epsilon \in[0,1]$. Indeed, during the period when the whole deficit is paid $(t=T)$, hidden information can appear that generates some cost, such as the government massaging the public accounting. In this way, $\epsilon$ reflects all elements (such as the political or economic context) that affect the effectiveness of the concession during the stabilization period. Therefore, the deficit level following the stabilization period $(t \geq T)$ is $\left(1-\epsilon \beta_{R}-\epsilon \beta_{D}\right) d(T)$, where $\epsilon$ denotes the probability of success of the concession $\beta_{i}$.

Finally, by (2) and (4), the amount of distortionary taxes $(\tau(t))$ becomes

$$
\tau(t)= \begin{cases}\gamma d(t)=\gamma g_{0} \exp \{(1-\gamma) r t\}, & t \in[0, \tilde{T}[, \\ \gamma\left(1-\beta_{R}-\beta_{D}\right) d(t)=\gamma g_{0}\left(1-\beta_{R}-\beta_{D}\right) \exp \{(1-\gamma) r t\}, & t \in[\tilde{T}, T[, \\ \left(1-\epsilon \beta_{R}-\epsilon \beta_{D}\right) d(T)=g_{0}\left(1-\epsilon \beta_{R}-\epsilon \beta_{D}\right) \exp \{(1-\gamma) r T\}, & t \geq T .\end{cases}
$$

\footnotetext{
${ }^{9}$ We can model, e.g., a negotiation round-table at $t=\tilde{T}$, during which each player simultaneously reveals his choice of the additional amount of tax to impose.
} 
Figure 1 shows the public deficit path. Initially $(t=0)$, due to the shock reducing tax revenues, the deficit equals public expenditures $(d(0)=g(0))$. Before the (exogenous) concessions round $(t \leq \tilde{T})$, by $(1)$ and (4), the public deficit evolves to $r b(t)+g(0)=$ $g(0) \exp \{(1-\gamma) r t\}$. At $t=\tilde{T}$, the first threshold effect appears: each group- $i$ can reduce its share $\beta_{i}$ of the deficit by accepting to pay an additional share of tax. From the stabilization period $(t \geq T)$, taxes increase until they equal the constant level of the public deficit $(\tau(T)=d(T))$. The second threshold effect relates to the success probability: the higher $\epsilon$ is, the greater the effectiveness of concessions, and the lower the constant level of the deficit.

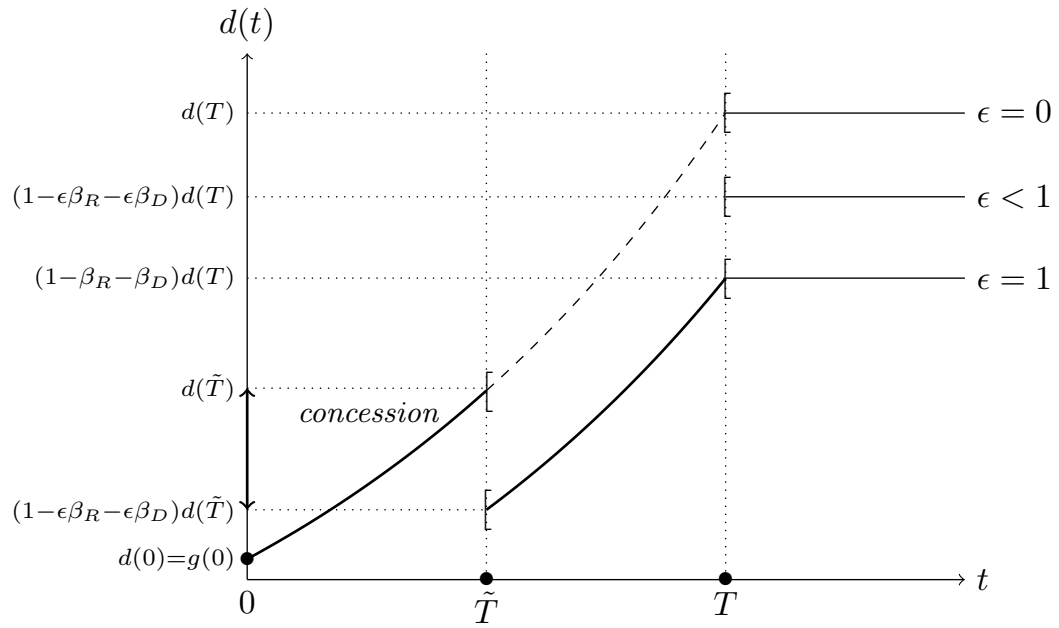

Figure 1: Public deficit path

\subsection{Agents' preferences}

Let us introduce the idiosyncratic random variable $\theta_{i}$, which reflects the individual loss of utility related to distortionary taxes. The cost $\theta_{i}$ is independently drawn from a distribution $F(\cdot)$ on $[\underline{\theta} ; \bar{\theta}]$, where $s:=\bar{\theta}-\underline{\theta}$ denotes the support's size. In imperfect information setup, $\theta_{i}$ is known only by group- $i$ itself, ${ }^{10}$, while other groups know the distribution $F$. Therefore, the instantaneous utility of the representative individual of group- $i$ is $u_{i}(t)=w_{i}-\theta_{i} \tau(t), \forall t<T$, where $w_{i}$ is the payoff reached absent distortion and reflects the constant level of income. ${ }^{11}$

After stabilization, taxes are non-distortionary and welfare loss disappears: $u_{i}(t)=$ $w_{i}, \forall t \geq T$. However, as is usual in wars of attrition, stabilization requires an agreement

\footnotetext{
${ }^{10}$ If all costs $\theta_{i}$ were public information, a pure-strategy equilibrium would be that the player with the higher cost would concede immediately, and there would be no war (see, e.g., Rubinstein, 1982). However, in an incomplete information game, a player concedes immediately only if he has the highest parameter $\bar{\theta}$.

${ }^{11}$ Their gross income is assumed to be constant over time and is then neglected in the analysis.
} 
between both groups on the distribution of tax burden. We suppose that one of the two groups (which becomes the loser) has to agree to pay a share $\alpha>1 / 2$ of the tax burden, while the other group (the winner) a fraction $1-\alpha$. In this way, $\alpha$ reflects the "degree of polarization in the society": the higher $\alpha$ is, the more unequally the tax burden will be, and the higher the degree of polarization.

Following Alesina and Drazen (1991), ${ }^{12}$ each group- $i$ pays half of the tax burden during the war, i.e., $w_{i}(t)=-\tau(t) / 2, \forall t \leq T$. Thus, its utility before the round of concessions $\left(u_{i}^{c}(t)\right)$ is

$$
u_{i}^{c}(t)=-\left(\frac{1}{2}+\theta_{i}\right) \tau(t)=-\gamma g_{0}\left(\frac{1}{2}+\theta_{i}\right) e^{(1-\gamma) r t}, \forall t \in[0, \tilde{T}[,
$$

and until the date of concession and stabilization $\left(u_{i}^{s}(t)\right)$,

$$
u_{i}^{s}(t)-\gamma g_{0}\left(1-\beta_{R}-\beta_{D}\right)\left(\frac{1}{2}+\theta_{i}\right) e^{(1-\gamma) r t}, \forall t \in[\tilde{T}, T[.
$$

The lifetime utilities of the loser and the winner from the date of stabilization onward, denoted by $V^{L}(t)$ and $V^{W}(t)$, respectively, are given by

$$
\begin{array}{ll}
V^{L}(t)=-\alpha g_{0}\left(1-\epsilon \beta_{R}-\epsilon \beta_{D}\right) e^{(1-\gamma) r t}, & \forall t \geq T, \\
V^{W}(t)=-(1-\alpha) g_{0}\left(1-\epsilon \beta_{R}-\epsilon \beta_{D}\right) e^{(1-\gamma) r t}, \forall t \geq T .
\end{array}
$$

Let us denote by $H(\cdot)$ the distribution of the opponent's optimal drop-out time and by $h(\cdot)$ the associated density function. ${ }^{13}$ Thus, using Eqs. (6) to (9), group- $i$ 's intertemporal expected utility is defined by

$$
\begin{aligned}
\mathrm{U}\left(T_{i}, \beta_{i}\right)= & {\left[1-H\left(T_{i}\right)\right]\left\{W_{i}+\int_{\tilde{T}}^{T_{i}} u_{i}^{s}(z) e^{-r z} d z+V^{L}\left(T_{i}\right) e^{-r T_{i}}\right\} } \\
& +\int_{x=\tilde{T}}^{x=T_{i}}\left\{W_{i}+\int_{\tilde{T}}^{x} u_{i}^{s}(z) e^{-r z} d z+V^{W}(x) e^{-r x}\right\} h(x) d x \\
& -c\left(\beta_{i}\right) \tau(\tilde{T}) e^{-r \tilde{T}}, \forall i \in\{D, R\},
\end{aligned}
$$

where $W_{i}:=\int_{0}^{\tilde{T}} u_{i}^{c}(z) e^{-r z} d z$ is the utility level before the round of concessions.

In (10), the first line represents group- $i$ 's expected utility if it drops out first (at time $T_{i}$ ), while the second line represents that if the other group drops out before $T_{i}$ (at time $x)$. Finally, the last line is the actual value of the cost of concession $\left(c\left(\beta_{i}\right)\right)$, where $c(\cdot)$ is assumed to be an increasing and (strictly) convex cost function. ${ }^{14}$

\footnotetext{
${ }^{12}$ Alesina and Drazen (1991) obtain this result after maximizing consumers' utility.

${ }^{13}$ These will depend on $F(\theta)$ and on the opponent's strategy.

${ }^{14}$ Indeed, concession $\beta_{i}$ actually generates an individual cost $c\left(\beta_{i}\right)$. Intuitively, group- $i$ 's announcement $\beta_{i}$ is the result of an internal consensus (i.e., among all agents belonging to the same group- $i$ ) on the willingness to pay an additional level of $\operatorname{tax} \beta_{i} \tau(\tilde{T})$ that generates costs, e.g., psychological or political costs.
} 


\subsection{Timing of Actions}

We consider a standard non-cooperative game. At the concessions round $(t=\tilde{T})$, each group has two strategic variables. Each group individually and simultaneously determines both its drop-out time $\left(T_{i}\right)$ and its concession $\left(\beta_{i}\right)$, according to the opponent's behavior.

In this way, group- $i$ 's programme is solved in three steps. The first-order conditions are computed in Subsection 2.4 (regarding the drop-out time) and Subsection 2.5 (regarding the concession level), and finally, Section 3 determines the unique global maximum.

\subsection{The optimal time of stabilization}

The optimal drop-out time for group- $i$, denoted by $T\left(\theta_{i}\right)$, is obtained by a symmetric Bayesian-Nash equilibrium, such as if the other group is behaving according to the function $T(\cdot)$, it is optimal to drop out according to $T\left(\theta_{i}\right)$.

Theorem 1. The unique monotonically decreasing function $T(\cdot)$ is defined by

$$
T^{\prime}(\theta)=-\frac{f(\theta)}{F(\theta)} \frac{(2 \alpha-1) / \gamma}{(1 / 2+\theta) \Delta_{\epsilon}\left(\beta_{R}, \beta_{D}\right)-\alpha r}, \forall \theta \in[\underline{\theta}, \tilde{\theta}]
$$

where $\Delta_{\epsilon}\left(\beta_{R}, \beta_{D}\right):=\left(1-\beta_{R}-\beta_{D}\right) /\left(1-\epsilon \beta_{R}-\epsilon \beta_{D}\right)$, and $T(\tilde{\theta})=\tilde{T}$.

Proof: See Appendix A.

From Theorem 1, the function $T(\cdot)$ is monotonically decreasing, namely, a high-cost group drops out first, and Eq. (11) can be written as ${ }^{15}$

$$
\left[-\frac{f(\theta)}{F(\theta)} \frac{1}{T^{\prime}(\theta)}\right](2 \alpha-1)=\gamma\left[\left(\frac{1}{2}+\theta\right) \Delta_{\epsilon}\left(\beta_{R}, \beta_{D}\right)-\alpha r\right]
$$

The RHS of (12) is the cost of waiting another instant to drop out, which is the difference between the utility loss related to distortionary taxation $(\gamma(1 / 2+\theta))$, adjusted by the relative cost of war $\left(\Delta_{\epsilon}\left(\beta_{D}, \beta_{R}\right)\right)$, and the discount value of the share $(\alpha)$ of the tax burden assumed by the losing group $(\gamma \alpha r)$. Indeed, $\Delta_{\epsilon}\left(\beta_{D}, \beta_{R}\right)$ denotes the ratio between "the cost of war" (i.e., the residual share of distortionary taxes at the concession round $\left.\left(1-\beta_{D}-\beta_{R}\right)\right)$ and "the cost of peace" (i.e., the fraction of the tax burden which must be paid at stabilization $\left.\left(1-\epsilon \beta_{D}-\epsilon \beta_{D}\right)\right)$. Therefore, the higher the cost of war relative to peace, the higher the ratio $\Delta_{\epsilon}(\cdot, \cdot)$ and the cost to wait another instant to drop out. Moreover, this ratio positively depends on the success probability $(\epsilon)$ : if $\epsilon=1$, we have $\Delta_{\epsilon}(\cdot, \cdot)=1$, as the reduction in distortionary taxation is identical to the decrease in the tax burden.

The LHS of (12) represents the expected gain from waiting another instant to drop out, which depends on the conditional probability that the opponent drops out (the

\footnotetext{
${ }^{15}$ Following Fudenberg and Tirole (1986), the boundary condition $(T(\tilde{\theta})=\tilde{T}$, with $\bar{\theta} \geq \tilde{\theta})$, allows us to exclude the possibility of multiple equilibria, namely, if group- $i$ is characterized by the maximum cost $\left(\theta_{i}=\tilde{\theta}\right)$, it will immediately drop out at beginning of the concessions round. In addition, as Alesina and Drazen (1991), to obtain an unique equilibrium, we suppose that $(1 / 2+\theta) \Delta_{\epsilon}\left(\beta_{R}, \beta_{D}\right)-\alpha r>0$, which is a mild assumption because in the rest of the paper, we assume a small interest rate (i.e., $r \approx 0$ ).
} 
hazard rate, in brackets), adjusted by the addition gain from victory $(2 \alpha-1) .{ }^{16}$ Finally, the optimal drop-out time occurs when that cost of waiting just equals the expected benefit from waiting. In addition, by considering the uniform distribution over $[\underline{\theta} ; \bar{\theta}]$, we obtain an explicit form of the function $T(\cdot)$.

Corollary 1. The function for the optimal drop-out time $T(\theta)$ is

$$
T(\theta)=\frac{(2 \alpha-1) / \gamma}{(1 / 2+\theta) \Delta_{\epsilon}\left(\beta_{R}, \beta_{D}\right)-\alpha r} \log \left(\left[\frac{\tilde{\theta}-\underline{\theta}}{\theta-\underline{\theta}}\right]\left[\frac{(1 / 2+\theta) \Delta_{\epsilon}\left(\beta_{R}, \beta_{D}\right)-\alpha r}{(1 / 2+\tilde{\theta}) \Delta_{\epsilon}\left(\beta_{R}, \beta_{D}\right)-\alpha r}\right]\right) .
$$

Proof: See Appendix A.

The expected date of debt stabilization, denoted by $T^{S E}$, is defined as the expected minimum between the individual drop-out times and is determined by the following Proposition. $^{17}$

Proposition 1. The expected time of stabilization $T^{S E}$ is given by

$$
T^{S E}=2 \int_{\underline{\theta}}^{\bar{\theta}} T(x) F(x) f(x) d x .
$$

Proof: See Appendix A.

In this Subsection, as concession levels $\left(\beta_{i}, i \in\{D, R\}\right)$ are given, we can ask how changes in the degree of concession affect the expected time of stabilization $\left(T^{S E}\right)$ by first defining the following case.

Definition 1. The case without concessions $\left(\beta_{i}=0\right)$ is called the "Alesina-Drazen $(A D)$ case", and we denote $T^{A D}(\theta):=\left.T(\theta)\right|_{\beta=0} \cdot{ }^{18}$

From Eq. (12), as $\partial \Delta_{\epsilon}(\cdot, \cdot) / \partial \beta_{i} \leq 0$, the expected cost decreases with $\beta_{i}$. Thus, the drop-out time $T(\cdot)$ given a positive concession $\left(\beta_{i}>0\right)$ is above Alesina-Drazen's drop-out time $T^{A D}(\cdot)$.

Corollary 2. The expected stabilization time $T^{S E}$ rises with the level of concessions $\beta_{i}$, $i \in\{D, R\}$.

Proof: See Appendix A.

Intuitively, the higher group- $i$ 's concession, the lower the deficit, public debt, and by (12), the cost of waiting another instant to stabilize. In turn, this marginal cost reduction increases each individual drop-out time, and, by (14), delays the expected time of stabilization. In other words, when the "purpose of the conflict" decreases (in our model, the public debt), the "intensity of war" declines, and the war is prolonged.

\footnotetext{
${ }^{16}$ Indeed, $2 \alpha-1$ reflects the additional share of the tax burden assumed by the losing group, as, by (8) and (9), $\left(V^{W}(T)-V^{L}(T)\right) / \tau(T)=2 \alpha-1$.

${ }^{17}$ Specifically, we have $T(\theta)<+\infty$ a.e., as, by $(13), T(\theta) \rightarrow+\infty$, when $\theta \rightarrow \underline{\theta}$, namely $\mathbb{P}\{T(\theta)=$ $+\infty\}=\mathbb{P}\{\theta=\theta\}=0$. Therefore, as $T^{S E}:=\mathbb{E}\left[\min _{\theta}\left\{T\left(\theta_{D}\right), T\left(\theta_{R}\right)\right\}\right] \leq \mathbb{E}[T(\theta)]<+\infty$, there is a positive value of the expected date of stabilization, as $0 \leq T^{S E}<+\infty$.

${ }^{18}$ Furthermore, the Alesina-Drazen case is also characterized when $\epsilon=1$, as $\epsilon=1 \Rightarrow \Delta_{\epsilon}(\cdot, \cdot)=1$. Therefore, by (12), the expected cost of waiting becomes: $(1 / 2+\theta)-\alpha r$.
} 


\subsection{The optimal level of concession}

This Subsection computes group- $i$ 's optimal concession $\beta_{i}^{*}, i \in\{D, R\}$. To this end, choosing a time $T_{i}$ as above is equivalent to choosing a value $\hat{\theta}_{i}$ and dropping out at time $T_{i}=T\left(\hat{\theta}_{i}\right)$. Therefore, the optimal amount $\beta_{i}^{*}$ is defined by

$$
\left\{\beta_{i}^{*}\left(\theta_{i}\right), \theta_{i}\right\}=\underset{\left(\beta_{i}, \hat{\theta}_{i}\right) \in[0 ; 1 / 2[\times[\underline{\theta}, \bar{\theta}]}{\operatorname{argmax}} \mathrm{U}\left(\beta_{i}, \hat{\theta}_{i}\right), \quad \forall i \in\{D, R\}
$$

The following Proposition establishes the first-order condition. ${ }^{19}$

Proposition 2. The optimal concession $\left(\beta_{i}^{*}\left(\theta_{i}\right), i \in\{D, R\}\right)$ satisfies

$$
\frac{(\tilde{\theta}-\theta)(2 \alpha-1)(1 / 2+\theta-\epsilon \alpha r)}{(\tilde{\theta}-\underline{\theta})\left[(1 / 2+\theta) \Delta_{\epsilon}\left(\beta_{R}, \beta_{D}\right)-\alpha r\right]}+\epsilon \alpha F(\tilde{\theta}) e^{-\gamma r \tilde{T}}=c^{\prime}\left(\beta_{i}\right) e^{-\gamma r \tilde{T}},
$$

where $\tilde{\theta}$ is such that $T(\tilde{\theta})=\tilde{T}$.

Proof. First, with the change in variables $T_{i}=T\left(\hat{\theta}_{i}\right),(10)$ becomes

$$
\begin{aligned}
& \mathrm{U}\left(\hat{\theta}_{i}, \theta_{i}, \beta_{i}\right)=F\left(\hat{\theta}_{i}\right)\left\{W_{i}+\frac{g_{0}}{r}\left(1 / 2+\theta_{i}\right)\left(1-\beta_{R}-\beta_{D}\right)\left[e^{-\gamma r T\left(\hat{\theta}_{i}\right)}-e^{-\gamma r T(\tilde{\theta})}\right]\right. \\
& \left.-\alpha g_{0}\left(1-\epsilon \beta_{R}-\epsilon \beta_{D}\right) e^{-\gamma r T\left(\hat{\theta}_{i}\right)}\right\} \\
& +\int_{x=\tilde{\theta}}^{x=\hat{\theta}_{i}}\left\{W_{i}+\frac{g_{0}}{r}\left(1 / 2+\theta_{i}\right)\left(1-\beta_{R}-\beta_{D}\right)\left[e^{-\gamma r T(x)}-e^{-\gamma r T(\tilde{\theta})}\right]\right. \\
& \left.-(1-\alpha) g_{0}\left(1-\epsilon \beta_{R}-\epsilon \beta_{D}\right) e^{-\gamma r T(x)}\right\} f(x) d x-c\left(\beta_{i}\right) g_{0} e^{-\gamma r T(\tilde{\theta})},
\end{aligned}
$$

where $\left\{\beta_{i}, \hat{\theta}_{i}\right\}$ are chosen by group- $i, i \in\{D, R\}$. By (17), differentiating with respect to $\beta_{i}$, the FOC is (where we drop the $i$ subscript)

$$
\begin{aligned}
\frac{\partial \mathrm{U}}{\partial \beta_{i}} & =F(\hat{\theta})\left\{-\frac{1}{r}\left(1 / 2+\theta_{i}\right) g_{0}\left[e^{-\gamma r T(\hat{\theta})}-e^{-\gamma r T(\tilde{\theta})}\right]+\alpha g_{0} \epsilon e^{-\gamma r T(\hat{\theta})}\right\} \\
& +\int_{\tilde{\theta}}^{\hat{\theta}}\left\{-\frac{1}{r}\left(1 / 2+\theta_{i}\right) g_{0}\left[e^{-\gamma r T(x)}-e^{-\gamma r T(\tilde{\theta})}\right]+(1-\alpha) g_{0} \epsilon e^{-\gamma r T(x)}\right\} f(x) d x \\
& -c^{\prime}\left(\beta_{i}\right) g_{0} e^{-\gamma r T(\tilde{\theta})}=0 .
\end{aligned}
$$

Note that directly, $\partial^{2} \mathrm{U} / \partial \beta_{i}^{2}=-c^{\prime \prime}\left(\beta_{i}\right) g_{0} e^{-\gamma r T(\hat{\theta})}<0$, as $c(\cdot)$ is strictly convex. Therefore, the FOC (18) becomes

$$
g\left(\hat{\theta}, \beta_{i}\right)=c^{\prime}\left(\beta_{i}\right) e^{-\gamma r T(\tilde{\theta})},
$$

where the function $g(\cdot, \cdot)$ is given by the following Lemma.

\footnotetext{
${ }^{19}$ To ensure that $\beta^{*}(\cdot) \geq 0$, as shown in the Proof of Proposition (2), we must assume that the support $[\underline{\theta}, \bar{\theta}]$ is large enough, namely that there is a critical level $\underline{s} \geq 1$ such that $s:=\bar{\theta}-\underline{\theta} \geq \underline{s}$.
} 
Lemma 1. The function $g:[\underline{\theta}, \tilde{\theta}] \times[0,1 / 2] \rightarrow \mathbb{R}$ is

$$
g\left(\hat{\theta}, \beta_{i}\right)=\frac{1}{\tilde{\theta}-\underline{\theta}}\left\{\frac{(\tilde{\theta}-\hat{\theta})(2 \alpha-1)(1 / 2+\theta-\epsilon \alpha r)}{(1 / 2+\theta) \Delta_{\epsilon}\left(\beta_{R}, \beta_{D}\right)-\alpha r}+\epsilon \alpha(\tilde{\theta}-\underline{\theta}) e^{-\gamma r T(\tilde{\theta})}\right\} .
$$

Proof: See Appendix B.

However, in the maximization with respect to $\hat{\theta}$, we have $\hat{\theta}=\theta$ when $\hat{\theta}$ is chosen optimally by the group with cost $\theta$; see the Proof of Theorem 1 in Appendix A. Thus, thanks to this optimality condition, the FOC (19) becomes $g\left(\theta, \beta_{i}\right)=c^{\prime}\left(\beta_{i}\right) e^{-\gamma r T(\tilde{\theta})}$, and finally, Eq. (16) immediately follows.

As $T(\tilde{\theta})=\tilde{T}$, by (11), the FOC (16) can be written as

$$
\epsilon \alpha F(\tilde{\theta}) e^{-\gamma r \tilde{T}}+\left[-\frac{(\tilde{\theta}-\theta)(\theta-\underline{\theta})}{\tilde{\theta}-\underline{\theta}} T^{\prime}(\theta)\right] \gamma(1 / 2+\theta-\epsilon \alpha r)=c^{\prime}\left(\beta_{i}\right) e^{-\gamma r \tilde{T}} .
$$

The LHS of (20) is the expected marginal gain from conceding and depends on two terms.

First, if group- $i, i \in\{D, R\}$, drops out at the concession round, i.e., $\theta_{i}=\tilde{\theta}$, it drops out first and will become the losing group with probability $F(\tilde{\theta})$. Consequently, this group will enjoy only of the reductions in the tax burden that it must pay $(\epsilon \alpha)$, and in discounted value, its marginal gain is simply $\epsilon \alpha F(\tilde{T}) e^{-\gamma r \tilde{T}}$.

Second, if group- $i$ drops out after the concession round, i.e. $\theta_{i}<\tilde{\theta}$, the marginal gain is increased by a second component. Indeed, an additional amount of concession decreases the utility loss related to distortionary taxation during the war, namely the "intensity of war" $(\gamma(1 / 2+\theta))$, net of the discounted gain from the peace $(\epsilon \alpha \gamma r)$. However, this marginal earning is linked to the stabilization delay: the longer the war's duration, the higher the earnings related to the reduction in the war's intensity. In this way, this marginal gain depends on a hazard rate (in brackets), which represents the increasing effect of the optimal stabilization time $\left(T^{\prime}(\theta)\right)$, adjusted by the uncertainty rate on the outcome of the war. ${ }^{20}$

Finally, the RHS of (20) represents the expected marginal cost of conceding, which is simply the discounted value of the marginal cost $\left(c^{\prime}\left(\beta_{i}\right)\right)$.

In addition, without loss of generality, we can easily suppose that the round of concessions is close to the initial instant $(t=0)$, i.e., $\tilde{T} \approx 0$; hence, $\tilde{\theta} \approx \bar{\theta}$, as $T(\tilde{\theta}) \approx \tilde{T}=0 .{ }^{21}$ Furthermore, to obtain analytic results, we suppose a small discount rate. In this way, the FOC (16) becomes

$$
\mathscr{G}\left(\beta_{i}, \theta\right)=\mathscr{C}\left(\beta_{i}\right), \forall i \in\{D, R\}
$$

\footnotetext{
20 Indeed, $(\tilde{\theta}-\theta)(\theta-\underline{\theta}) /(\tilde{\theta}-\underline{\theta})$ can be equated to $f(\theta) F(\theta)[1-F(\theta)]$. Hereafter, this will be the case because we will assume that $\tilde{T}=0$, namely, $\tilde{\theta}=\bar{\theta}$. Thus, as $F\left(\theta_{i}\right)$ (resp. $1-F\left(\theta_{i}\right)$ ) denotes the probability that group- $i$ loses (resp. wins) the war, the clearer the outcome of war is (i.e., the closer $F(\theta)$ is to 0 or 1 ), the lower the uncertainty rate is. Moreover, we consider the random variable $Z_{i}$, which equals 1 if group- $i$ loses, 0 otherwise. Thus, as $Z_{i}$ follows Bernoulli's law with success probability $F\left(\theta_{i}\right)$, then $F\left(\theta_{i}\right)\left(1-F\left(\theta_{i}\right)\right.$ is the variance of $Z_{i}$. Consequently, the uncertainty rate $f\left(\theta_{i}\right) F\left(\theta_{i}\right)\left[1-F\left(\theta_{i}\right)\right]$ measures the dispersion of $Z_{i}$, namely, the volatility of the war's outcome.

${ }^{21}$ Effectively, if $\tilde{T}>0$, our results are unchanged because the period before the initial time $(t=0)$ and the concession time $(t=\tilde{T})$ is neglected in the analysis. Indeed, the utility $u_{i}^{c}(t), \forall t<\tilde{T}$ is not present in the equilibrium (12).
} 
where $\mathscr{C}\left(\beta_{i}\right):=c^{\prime}\left(\beta_{i}\right)$ is the marginal cost and $\mathscr{G}\left(\beta_{i}, \theta\right):=(2 \alpha-1) F(\theta) / \Delta_{\epsilon}\left(\beta_{R}, \beta_{D}\right)+\epsilon \alpha$ the expected marginal gain, which positively depends on the probability of losing the war $(F(\theta))$. Indeed, the higher $\theta_{i}$ is, the lower $T\left(\theta_{i}\right)$ and the chances of winning are. At the limit, when group- $i$ drops out at the concessions round $\left(\theta_{i}=\tilde{\theta}\right)$, it becomes the losing group and benefits only from the reduction in the tax burden that it must pay $(\epsilon \alpha)$.

The optimal concession $\left(\beta_{i}^{*}\right)$ occurs when the marginal cost equals the marginal gain, i.e., $\mathscr{C}\left(\beta_{i}^{*}\right)=\mathscr{G}\left(\beta_{i}^{*}, \theta_{i}\right), \forall i \in\{D, R\}$. As $\mathscr{G}\left(\beta_{i}, \theta_{i}\right)$ negatively depends on $\theta_{i}, \beta_{i}$ also depends on $\theta_{i}$, i.e., $\beta_{i}:=\beta_{i}\left(\theta_{i}\right)$. Additionally, in the symmetric equilibrium, both groups drop out according to the same function $T(\cdot)$, namely, they will also concede according to the same function $\beta(\cdot)$, i.e., $\beta_{D}\left(\theta_{D}\right)=\beta_{R}\left(\theta_{R}\right)=: \beta\left(\theta_{i}\right)$, where $\beta^{\prime}(\cdot) \leq 0$. In this way, the function $\beta(\theta)$ is a symmetric Bayesian-Nash equilibrium if and only if it maximizes the inter-temporal utility function. In the remainder of the paper, we consider a quadratic cost function, namely, $c\left(\beta_{i}\right)=\beta_{i}^{2}, i \in\{D, R\}$. Consequently, we establish the following Proposition.

Proposition 3. There is a critical degree of polarization $\bar{\alpha}_{\epsilon} \in[1 / 2,1]$, such that, if $\alpha \leq \bar{\alpha}_{\epsilon}$, there are two levels of concession $(\beta(\theta), \bar{\beta}(\theta), \forall \theta \in[\underline{\theta}, \bar{\theta}])$, which respect the first-order condition $(21)$, where $\bar{\beta}(\cdot) \geq \beta(\cdot)$.

Proof: See Appendix B.

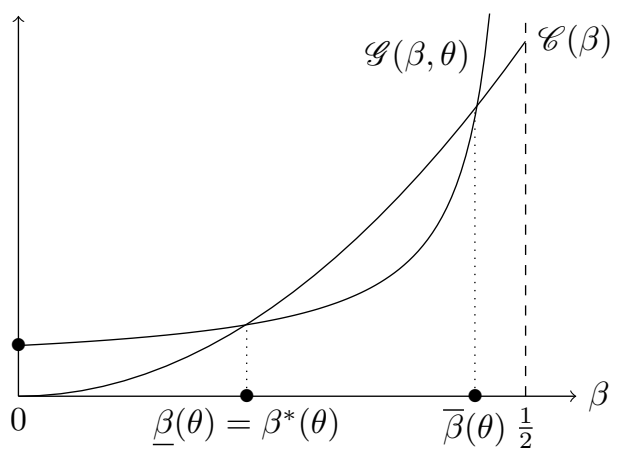

a. if $\bar{\alpha}_{\epsilon} \geq \alpha$

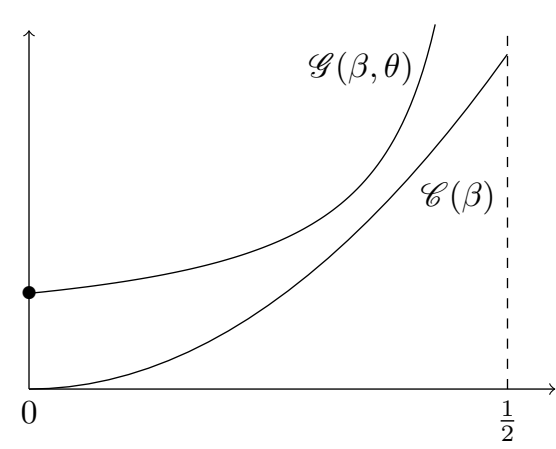

b. if $\bar{\alpha}_{\epsilon}<\alpha$

Figure 2: Optimally condition for $\theta \in[\underline{\theta}, \bar{\theta}]$.

As the marginal gain from conceding increases with $\alpha$, while the marginal cost is independent of $\alpha$, there is a critical degree of polarization $\left(\bar{\alpha}_{\epsilon}\right)$ ensuring that there are two crossing-points: $\beta(\theta)$, and $\bar{\beta}(\theta)$, as shown in Figure $2 \mathrm{a}^{22}$ Intuitively, when the

\footnotetext{
${ }^{22}$ Each marginal function $(\mathscr{G}(\cdot, \theta)$, and $\mathscr{C}(\cdot), \forall \theta \in[\bar{\theta}, \underline{\theta}])$ is described by an increasing and convex curve, where the marginal gain is initially above the marginal cost, as $\mathscr{G}(0, \theta)=F(\theta)(2 \alpha-1)+\epsilon \alpha \geq 0=\mathscr{C}(0)$. Nevertheless, for small values of concession $(\beta \rightarrow 0)$, the slope of the marginal gain is less than the slope of the marginal cost, while when $\beta \rightarrow 1 / 2$, the marginal gain jumps up $(\mathscr{G}(\beta, \theta) \rightarrow+\infty)$, as $\Delta_{\epsilon}(\beta, \beta) \rightarrow+\infty$.
} 
society is strongly polarized, namely $\alpha>\bar{\alpha}_{\epsilon}$, the losing will assume a great share of the tax burden at the time of stabilization. In this way, as concession delays the end of the war, the gain related to the increasing effect of the stabilization time is higher than the marginal cost, as shown in Figure 2b. Thus, without critical points, the optimal concession is the corner solution: $\beta^{*}=1 / 2$.

This Subsection computed the first-order condition relative to the concession level and Subsection 2.4 that relative to the drop-out time. The following Section solves these two optimally conditions and obtains the unique global maximum.

\section{Equilibrium and Analysis}

This Section establishes the symmetric Bayesian-Nash equilibrium in the following Theorem and presents some comparative statics.

Theorem 2. (Symmetric Equilibrium) There are upper limits $\bar{\theta}^{*}$ and $\bar{\alpha}_{\epsilon}^{*}$ ensuring that $\left(T^{*}(\theta), \beta^{*}(\theta)\right)$ is the unique maximum of the utility function, such that

- If $\alpha \leq \bar{\alpha}_{\epsilon}^{*}$ :

$$
\begin{aligned}
& \beta^{*}(\theta)=\underline{\beta}(\theta), \\
& T^{*}(\theta)=\frac{(\bar{\theta}-\underline{\theta}) \mathscr{C}\left(\beta^{*}(\theta)\right)}{(\bar{\theta}-\theta)(1 / 2+\theta) \gamma} \log \left\{\frac{(\bar{\theta}-\underline{\theta})(1 / 2+\theta)}{(\theta-\underline{\theta})(1 / 2+\bar{\theta})}\right\}, \forall \theta \in[\underline{\theta} ; \bar{\theta}] .
\end{aligned}
$$

- If $\alpha>\bar{\alpha}_{\epsilon}^{*}: \beta^{*}(\theta)=1 / 2$, and $T^{*}(\theta)=0$.

Proof: See Appendix B.

From Theorem 2, there is a unique maximum of the utility function if $\bar{\theta} \leq \bar{\theta}^{*}{ }^{23}$

On the one hand, if the society is highly polarized, i.e., $\alpha>\bar{\alpha}_{\epsilon}^{*}$, according to Proposition 3, an additional amount of concession always yields the greatest gain; therefore, in the symmetric equilibrium, both groups choose to concede the maximum level, i.e., $\beta^{*}(\cdot)=1 / 2$. In this way, the public debt is stabilized during the concession round, as the deficit is entirely financed by taxes. Thus, the conflict disappears $\left(T^{*}(\cdot)=0\right)$ : at the initial period $t=0$ (because $\tilde{T}=0$ ), each group pays the half of the stabilization burden, namely $\alpha=1 / 2$. In other words, $\bar{\alpha}_{\epsilon}^{*}$ denotes the maximum degree of polarization in society, ensuring the existence of a war of attrition.

On the other hand, each group must assume a non-zero fraction of the collective object of the conflict (namely, the tax burden) to obtain an interior solution. Effectively, when the society is weakly polarized, i.e., $\alpha \leq \bar{\alpha}_{\epsilon}^{*}$, there is a unique global maximum $\left(\beta^{*}(\theta), T^{*}(\theta)\right)$, where $\beta^{*}(\theta)$ is the lower value $\beta(\theta)$, as shown in Figure 2a. Additionally, the optimal stabilization time $T^{*}(\theta)$ is connected to $\beta^{*}(\theta)$ through the marginal cost of conceding $\mathscr{C}(\theta)$ : the more costly one unit of concession is, the more this unit delays the stabilization. The intuition is as follows. The goal of the concession is to prolong the

\footnotetext{
${ }^{23}$ The upper limit $\bar{\theta}^{*}$ ensures that the growth rate of the marginal cost $c^{\prime}(\cdot)$ is weaker than the loss of utility due to distortionary taxation. Effectively, Appendix B shows that $\theta<\bar{\theta} \Leftrightarrow-(1 / 2+\theta)>-c^{\prime \prime}(\beta)$, $\forall \theta \in[\bar{\theta}, \underline{\theta}]$.
} 
war to delay the time at which every group will assume the tax burden. Thus, by (12), the higher the marginal cost to concede is, the higher the expected marginal cost to drop out and the greater the delay of the optimal stabilization time.

Finally, Figure 3 depicts the Bayesian-Nash equilibrium if $\alpha \leq \bar{\alpha}_{\epsilon}^{*}$. The optimal concession $\beta^{*}(\theta)$ is drawn on the bottom graph and the optimal time of stabilization $T^{*}(\theta)$ on the upper graph, where the stabilization time of Alesina-Drazen $T^{A D}(\theta)$ is represented by the dashed curve.

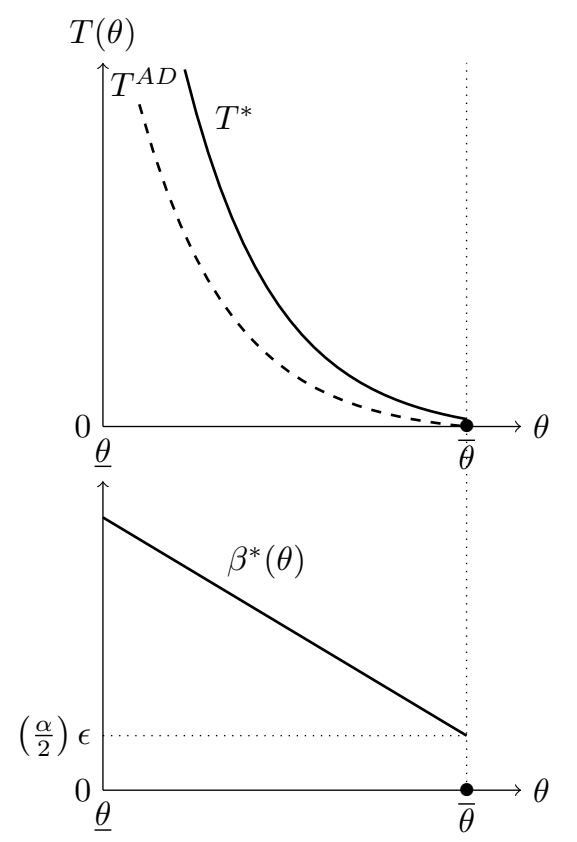

Figure 3: The symmetric equilibrium for $\alpha \leq \bar{\alpha}_{\epsilon}^{*}$.

We can now ask how various changes in the parameters impact the optimal concession and the delay in stabilization. ${ }^{24}$

Proposition 4. The optimal concession decreases with the cost related to the distortionary taxation $\theta$.

Proof: By $(23)$, clearly $T^{*^{\prime}}(\cdot) \leq 0$.

From Eq. (21), the expected marginal gain from conceding rises with the probability of losing the war $(F(\theta))$. Therefore, the greater the loss of group's utility related to distortionary taxation, the higher its risks of loosing, and the greater its incentive to delay the war's conclusion. Thus, concession is a strategic variable for both groups to

${ }^{24}$ Formally, we have $\partial\left\|T^{*}(\cdot)-T^{A D}(\cdot)\right\| / \partial \beta \geq 0$, where $\|\cdot\|$ is the standard $L^{1}$-norm. 
control the stabilization delay (i.e., the war's duration). In addition to the decision to assume the tax burden, i.e., the choice to drop out, each group can strategically reduce the deficit level somewhat for the purpose of forestalling the peace period, which requires to pay the totality of the tax burden. At the limit, when $\theta=\bar{\theta}$, namely when a group drops out at the concessions round, the war ends: $T^{*}(\bar{\theta})=T^{A D}(\bar{\theta})=0$. However, the group concedes a positive amount: $\beta(\bar{\theta})=\epsilon \alpha / 2$. Indeed, according to Theorem 2 , the optimal concession $\left(\beta^{*}\right)$ is simply the share of the stabilization burden assumed by each group $(\alpha / 2)$ reduced with probability $\epsilon .^{25}$

Proposition 5. The optimal concession rises with the degree of polarization $\alpha$.

Proof: The proof of Proposition 3 in Appendix B rewrites the optimally condition (21) using the implicit function $\varphi\left(\theta, \beta_{i}\right)=0$, where $\varphi\left(\theta, \beta_{i}\right)=\epsilon \alpha-c^{\prime}\left(\beta_{i}\right)+F(\theta)(2 \alpha-$ $1) / \Delta_{\epsilon}\left(\beta_{D}, \beta_{D}\right)$. Therefore, we obtain, $\partial_{\alpha} \varphi(\theta, \beta)=\epsilon+2 F(\theta)(1-2 \epsilon \beta) /(1-2 \beta) \geq 0$ for each $(\theta, \beta) \in[\bar{\theta}, \underline{\theta}] \times[0,1 / 2[$ and each $\epsilon \in[0,1]$.

Following Alesina and Drazen (1991), the difference in the share of the stabilization burden $(\alpha)$ denotes the degree of political polarization in the society. If $\alpha$ is close to $1 / 2$, the society is characterized by high political cohesion, as the burden of stabilization is shared relatively equally, while if $\alpha$ is close to $\bar{\alpha}_{\epsilon}^{*}$, the society is more polarized (namely, less cohesive) because the burden is very unequally allocated. In this way, when $\alpha$ rises, the expected marginal gain from conceding is larger, and both groups remain in the war longer. This result agrees with many works in political economy (see the excellent survey by Alesina and Perotti, 1994), which argue that large coalition governments delay public debt stabilization. Specifically, Roubini and Sachs (1989) show that countries characterized by coalitions composed of many political parties have larger deficits. ${ }^{26}$ More recently, Huber et al. (2003) suggest that coalitions with equally strong parties yield more deficits than coalitions with one dominant party that delays debt stabilization. In this respect, our model establishes that the greater the political polarization, the higher the concessions and the greater the delay of debt stabilization, which is in line with Spolaore (1993). ${ }^{27}$

Finally, to establish a simple benchmark with the Nash equilibrium, the following Section determines the Social Welfare Equilibrium.

\section{Social Welfare}

This Section computes the social first-best outcome in two steps.

\footnotetext{
${ }^{25}$ In addition, Lemma 4 in Appendix B establishes that the optimal concession $\beta^{*}(\cdot)$ linearly rises with the probability $\epsilon$. Specifically, there is a dual effect of the success probability $\epsilon$ on the marginal gain. By (20), on the one hand, $\epsilon$ increases the fraction of tax burden, which is reduced by making a concession. On the other hand, $\epsilon$ decreases the net discount value of the loss of utility during the war Thus, Lemma 4 argues that the positive effect offsets the negative effect.

${ }^{26}$ Some articles question the conclusions of Roubini and Sachs; see, e.g., de Haan and Sturm (1997).

${ }^{27}$ For Spolaore, the stabilization is delayed by an increase in the public deficit and debt, while in our setup, the delay arises from a decrease in the deficit and debt. Indeed, the deficit being reduced through concessions makes it possible to decrease the cost of remaining at war (as the distortionary taxation becomes smaller), which delays the end of the conflict, namely debt stabilization.
} 
Step 1. From the social planner's perspective, all groups have equal weight. In this way, we ignore, first, the direct dependance of groups' utility on the individual cost $(\theta)$. Thus, following Drazen and Grilli (1993), at symmetric equilibrium, the social welfare if the debt is stabilized at time $T$ is given by

$$
L(T, \beta)=\int_{0}^{T} u_{i}^{s}(z) e^{-r s} d s-2 \tau(\tilde{T}) c\left(\frac{\beta}{2}\right) e^{-r \tilde{T}}+\Delta V(\beta) e^{-r T},
$$

where $\Delta V(\beta):=\left(V^{L}+V^{W}\right) / 2$ is the mean of the lifetime utility from the date of stabilization, which for simplicity is assumed to be independent of the time $T$. Thus, the expected social welfare, denoted by $\operatorname{ESW}(\beta)$, is given by the expectation of $L(T, \beta)$ taken over the distribution of possible time $T$ values. Therefore, we have

$$
\operatorname{ESW}(\beta)=\int_{0}^{+\infty} L(T, \beta) g(T) d T
$$

where $G(T)$ is the cumulative distribution if one group drops out at time $T$, and $g(T)$ is the associated density function.

Step 2. To obtain an analytic form of the distribution $g(\cdot)$, we change the variable $T$ on $\theta$, such that $T=T(\theta)$. Thus, $1-G(T(\theta))$ becomes the probability that both groups drop out after time $T(\theta)$, and as $g(T)=d G(T) / d T$, we have $g(T(\theta))=2 F(\theta) f(\theta){ }^{28}$ Namely, (25) becomes

$$
\operatorname{ESW}(\beta)=2 \int_{\underline{\theta}}^{\bar{\theta}} L(T(\theta), \beta) F(\theta) f(\theta) d \theta .
$$

Using Eq. (26), the social planner determines the amount $\beta^{S W}$ that maximizes expected social welfare, namely $\beta^{S W}:=\operatorname{argmax}_{\beta \in[0,1 / 2]} \operatorname{ESW}(\beta)$.

Proposition 6. There is a small critical level $\epsilon_{0} \approx 0$ such that, if $\epsilon_{0} \leq \epsilon, \beta^{S W}=1 / 2$.

Proof: See Appendix C.

Intuitively, if pure failure is impossible, namely $\epsilon \geq \epsilon_{0} \approx 0$, the social planner liquidated all deficits at the initial instant $(\beta=1 / 2)$. In other words, public debt is stabilized during the round of concessions, as the deficit is entirely covered by taxes. The social welfare is maximized when the end of the war (the stabilization) occurs as soon as possible without a loser or winner, as in the symmetric Nash equilibrium when society is highly polarized, i.e., $\alpha>\bar{\alpha}_{\epsilon}^{*}$. Moreover, if $\alpha \leq \bar{\alpha}_{\epsilon}^{*}$, the optimal concession given by the Nash equilibrium is characterized by a sub-liquidation of debt $\left(\beta^{*}(\cdot)<\beta^{S W}=1 / 2\right)$ because in the Nash equilibrium, the outcome of the war and the associated loss of welfare, is risked, as it depends on the random individual cost of war.

\footnotetext{
${ }^{28}$ Let $\theta_{0} \in[\underline{\theta}, \bar{\theta}]$. Thus, we can write $1-G\left(T\left(\theta_{0}\right)\right)=\mathbb{P}\left(\left\{\forall i \in\{D, R\}, T\left(\theta_{i}\right)>T\left(\theta_{0}\right)\right\}\right)=\mathbb{P}\left(\theta_{R}<\right.$ $\left.\theta_{0}, \theta_{D}<\theta_{0}\right)$, as $T(\cdot)$ is a decreasing function. As $\theta_{R}$ and $\theta_{D}$ are independent, we obtain $1-G\left(T\left(\theta_{0}\right)\right)=$ $F\left(\theta_{0}\right)^{2}$.
} 


\section{Conclusion}

This paper introduces a round of concessions into a standard war of attrition. We model concessions as agreements to pay additional taxes and show that they delay the end of the war, namely debt stabilization. The intuition is that political groups concede to delay the moment at which they will be required to pay the full tax burden, thus generating considerable welfare loss. In this way, each group strategically agrees to pay additional taxes during the pre-stabilization period to prolong the conflict over the allocation of this burden. In addition, as remaining at war is less expensive than dropping out first, every player also concedes to delay the risky war outcome. Consequently, during the concessions round, each group optimally computes (i) its drop-out time and (ii) its level of concessions, according to the opponent's behavior. The result is an unique, symmetric mixed-strategy Nash equilibrium, in which the optimal drop-out time is positively associated with the optimal amount of concessions through the marginal cost of conceding.

In addition, this paper joins Spolaore (1993) and a substantive literature (Alesina and Tabellini, 1989, 1990b; Roubini and Sachs, 1989; Huber et al., 2003, among others), which argues that large coalition governments delay public debt stabilization. Their main explanation is that the larger the number of parties in coalition, the greater the difficulty in reaching agreements and reforms concerning the government budget and, in turn, the higher the deficits and debt. However, our model develops another mechanism. When a government is consists of a larger coalition, the tax burden will be more unequally distributed, which increases the expected cost of stabilization and induces each group to concede more to delay stabilization.

Our setup contributes to explaining the failures of austerity measures in the stabilization of public debt. In the well-known Greek debt crisis, drastic budget-reducing measures were implemented by the government of A.Samaras (2012-2015) through two austerity plans, which were also requested by the IMF and the European Union in return for bailouts. In this paper, governments provide austerity measures to delay the resolution of expensive problems (namely, public debt stabilization) to, e.g., continue negotiations with international institutions for future bailouts. Therefore, our model joins studies arguing that the multiplicity of austerity plans adopted during the Samaras administration can primarily be explained by political and electoral concerns. ${ }^{29}$ In addition, other famous examples are fiscal adjustments and reforms requested by the IMF from developing countries, e.g., certain Latin American countries in the 1980s. ${ }^{30}$ Following Vreeland (2003), who argues that austerity plans are also used to advance electoral and opportunistic aims, our model establishes that fiscal adjustments can constitute strategic concessions to delay debt stabilization and can be used remain in IMF programmes, without resolving internal structural problems.

Finally, our model may lead to interesting prospects for future research. First, the introduction of a round of concessions into standard war of attrition models might be studied in other contexts, specifically to model international negotiations. In our setup, one political group can be identified as a national government and the other as an international institution, and a war of attrition can occur over the negotiation of bailouts,

\footnotetext{
${ }^{29}$ See, e.g., Malkoutzis (2012); Katsikas (2012); Ardagna and Caselli (2014).

${ }^{30}$ Some cases are detailed in Vreeland (2003), pp. 20:51
} 
where the concession can represent an agreement to default on a part of the national debt. Thus, our setup would allow a fresh analysis of the debates between the "Troika" and Athens over the sustainability of Greek debt. Second, concessions occurring in wars of attrition can be modeled in an asymmetric information setup. In this way, a group's concession will have another function, namely a signalling effect sent to opponents regarding the group's capacity to abandon the conflict. In this game, each player will revise his optimal drop-out time based on the level of the opponents' concession. Third, the introduction of a strategic concession would allow to connect wars of attrition under the standard voting model of Lindbeck and Weibull (1987) and Persson and Tabellini (2000). Intuitively, debt stabilization requires a considerable loss of utility for voters due to the tax burden and reduces the reelection probability of the party in office. Therefore, an incumbent politician can delay stabilization until after the next election through a strategic concession that delays the resolution of the war of attrition.

\section{References}

Aghion, P., Bolton, P.P., 1990. Government Domestic Debt and the Risk of Default: A PoliticalEconomic Model of the Strategic Role of Government Debt, in: Dornbusch, R., Draghi, M. (Eds.), Public Debt Management: Theory and History. Cambridge University Press, NY, pp. 315-344.

Alesina, A., Drazen, A., 1991. Why are Stabilizations Delayed? American Economic Review 81, 11701188.

Alesina, A., Passalacqua, A., 2015. The Political Economy of Government Debt. NBER Working Papers 21821.

Alesina, A., Perotti, R., 1994. The Political Economy of Budget Deficits. NBER Working Papers 4637.

Alesina, A., Tabellini, G., 1989. External Debt, Capital Flight and Political Risk. Journal of International Economics 27, 199-220.

Alesina, A., Tabellini, G., 1990a. A Positive Theory of Fiscal Deficits and Government Debt. Review of Economic Studies 57, 403-414.

Alesina, A., Tabellini, G., 1990b. Voting on the Budget Deficit. American Economic Review 80, 37-49.

Ardagna, S., Caselli, F., 2014. The Political Economy of the Greek Debt Crisis: A Tale of Two Bailouts. American Economic Journal: Macroeconomics 6, 291-323.

Backus, D., Driffill, J., 1985. Rational Expectations and Policy Credibility Following a Change in Regime. Review of Economic Studies 52, 211-121.

Bliss, C., Nalebuff, B., 1984. Dragon-Slaying and Ballroom Dancing: The Private Supply of a Public Good. Journal of Public Economics 23, 1-12.

Bulow, J., Kemperer, P., 1999. The Generalized War of Attrition. American Economic Review 89, $175-189$.

Carré, M., 2000. Debt Stabilization with a Deadline. European Economic Review 44, 71-90.

Casella, A., Eichengreen, B., 1996. Can Foreign Aid Accelerate Stabilisation? Economic Journal 106, 605-619.

Drazen, A., 2000. Political Economy in Macroeconomics. Princeton University Press, Princeton.

Drazen, A., Grilli, V., 1993. The Benefits of Crises for Economic Reform. American Economic Review $83,588-608$.

Duroselle, J.B., 2002. La Grande Guerre des Français 1914-1918. Perrin, Paris.

Foley, R., 2005. German Strategy and the Path to Verdun: Erich Von Falkenhayn and the Development of Attrition, 1870-1916. Cambridge University Press, Cambridge.

Fudenberg, D., Tirole, J., 1986. A Theory of Exit in Duopoly. Econometrica 54, 943-960.

Guidotti, P., Vegh, C., 1999. Losing Credibility: The Stabilization Blues. International Economic Review 40, 23-51.

de Haan, J., Sturm, E., 1997. Political and Economic Determinants of OECD Budget Deficits and Government Expenditures: A Reinvestigation. European Journal of Political Economy 13, 739-750.

Huber, G., Kocher, M., Sutter, M., 2003. Government Strength, Power Dispersion in Governments and Budget Deficits in OECD Countries. A Voting Power Approach. Public Choice 116, 333-350.

Katsikas, D., 2012. The Greek Crisis and the Search for Political Leadership. The International Spectator: Italian Journal of International Affairs 47, 49-56. 
Krishna, V., Morgan, J., 1997. An Analysis of the War of Attrition and the All-Play Auction. Journal of Economic Theory 72, 343-362.

Lane, P., 2012. The European Sovereign Debt Crisis. Journal of Economic Perspectives 26, 49-67.

Lindbeck, A., Weibull, J., 1987. Balanced-Budget Redistribution as the Outcome of Political Competition. Public Choice 52, 273-297.

Malkasian, C., 2002. A History of Modern Wars of Attrition. Westport, Praeger.

Malkoutzis, N., 2012. Greece's Painful Political Transition. Analysis of the Upcoming National Elections. International Policy Analysis. Friedrich Ebert Stiftung URL: http://library.fes.de/pdf-files/id/ $09061 . \mathrm{pdf}$.

Martinelli, C., Escorza, R., 2007. When are Stabilizations Delayed? Alesina-Drazen Revisited. European Economic Review 51, 1223-1245.

Milesi-Ferretti, G., Spolaore, E., 1994. How Cynical Can an Incumbent Be? Strategic Policy in a Model of Government Spending. Journal of Public Economics 55, 121-140.

Nalebuff, B., Riley, J., 1985. Asymetric Equilibria in the War of Attrition. Journal of Theoretical Biology 113, 517-527.

Padovano, F., Venturi, L., 2001. Wars of Attrition in Italian Government Coalitions and Fiscal Performance: 1948-1994. Public Choice 109, 15-54.

Persson, T., Tabellini, G., 2000. Political Economics. Explaining Economic Policy. The MIT Press, MA. Philpott, W., 2014. War of Attrition: Fighting the First World War. The Overlook Press, NY.

Renoton-Beine, N., 2004. La Colombe et les Tranchées : Les tentatives de paix de Benoît XV pendant la Grande Guerre. Editions du Cerf, Paris.

Riley, J., 1980. Strong Ecolutionnary Equilibrium and the War of Attrition. Journal of Theoretical Biology 82, 383-400.

Roubini, N., Sachs, J., 1989. Political and Economic Determinants of Budget Deficits in the Industrial Democracies. European Economic Review 33, 903-938.

Rubinstein, A., 1982. Perfect Equilibrium in a Bargaining Model. Econometrica 50, 97-109.

Scherer, A., Grunewald, J., 1962. L'Allemagne et les problèmes de la paix pendant la Première Guerre mondiale. Documents extraits des archives de l'Office allemand des Affaires étrangères. Press Universitaire de France, Paris.

Smith, J., 1974. Theory of Games and the Evolution of Animal Conflicts. Journal of Theoretical Biology 47, 209-221.

Spolaore, E., 1993. Macroeconomic Policy, Institutions and Efficiency. Ph.D. Dissertation, Harvard University, Harvard.

Tabellini, G., 1988. Centralized Wage Setting and Monetary Policy in a Reputational Equilibrium. Journal of Money, Credit and Banking 20, 102-118.

Vreeland, J., 2003. The IMF and Economic Development. Cambridge University Press, NY.

\section{Appendix A}

Proof of TheOrem 1.

We adopt a two-step proof. The first step proves that the optimal concession time $T_{i}$ is monotonically decreasing in $\theta_{i}$, while the second step determines the symmetric Nash equilibrium.

Step 1. Differentiating (10) with respect to $T_{i}, i \in\{D, R\}$, we obtain

$$
\begin{aligned}
\frac{\partial \mathrm{U}}{\partial T_{i}}= & e^{-r T_{i}}\left\{h\left(T_{i}\right)\left[V^{W}\left(T_{i}\right)-V^{L}\left(T_{i}\right)\right]\right. \\
& \left.+\left[1-H\left(T_{i}\right)\right]\left[u_{i}^{s}\left(T_{i}\right)+\left(V^{L}\right)^{\prime}\left(T_{i}\right)-r V^{L}\left(T_{i}\right)\right]\right\} .
\end{aligned}
$$

By (6) until (9), (A.1) becomes $\partial \mathrm{U} / \partial T_{i}=g_{0} e^{-\gamma r T_{i}}\left\{h\left(T_{i}\right)(2 \alpha-1)\left(1-\epsilon \beta_{1}-\epsilon \beta_{2}\right)\right.$ $\left.+\gamma\left[1-H\left(T_{i}\right)\right]\left[\alpha r\left(1-\epsilon \beta_{R}-\epsilon \beta_{D}\right)-\left(1 / 2+\theta_{i}\right)\left(1-\beta_{R}-\beta_{D}\right)\right]\right\}$. Hence,

$$
\frac{\partial^{2} \mathrm{U}}{\partial T_{i}^{2}}=-\gamma g_{0}\left[1-H\left(T_{i}\right)\right]\left(1-\beta_{R}-\beta_{D}\right) e^{-\gamma r T_{i}}<0 .
$$


Thus, by (A.2), $\partial \mathrm{U} / \partial T_{i}$ is deceasing in $\theta_{i}$; therefore, the optimal concession time $T_{i}$ is monotonically decreasing in $\theta_{i}$.

Step 2. Using (6) until (9), the expected utility (10) becomes

$$
\begin{aligned}
\mathrm{U}\left(T_{i}, \beta_{i}\right) & =\left[1-H\left(T_{i}\right)\right]\left\{W_{i}+\frac{g_{0}}{r}\left(1 / 2+\theta_{i}\right)\left(1-\beta_{R}-\beta_{D}\right)\left[e^{-\gamma r T_{i}}-e^{-\gamma r \tilde{T}}\right]\right. \\
& \left.-\alpha g_{0}\left(1-\epsilon \beta_{R}-\epsilon \beta_{D}\right) e^{-\gamma r T_{i}}\right\} \\
& +\int_{x=\tilde{T}}^{x=T_{i}}\left\{W_{i}+\frac{g_{0}}{r}\left(1 / 2+\theta_{i}\right)\left(1-\beta_{R}-\beta_{D}\right)\left[e^{-\gamma r x}-e^{-\gamma r \tilde{T}}\right]\right. \\
& \left.-(1-\alpha) g_{0}\left(1-\epsilon \beta_{R}-\epsilon \beta_{D}\right) e^{-\gamma r x}\right\} h(x) d x-c\left(\beta_{i}\right) g_{0} e^{-\gamma r \tilde{T}} .
\end{aligned}
$$

Now, we suppose that the other group characterized by the cost $\theta$ drops out according to $T(\theta)$. Thus, choosing a time $T_{i}$ as above would be equivalent to choosing a value $\hat{\theta}_{i}$ and stabilizing at time $T_{i}=T\left(\hat{\theta}_{i}\right)$; hence, Eq. (A.3) becomes ${ }^{31}$

$$
\begin{aligned}
\mathrm{U}\left(\hat{\theta}_{i}, \theta_{i}, \beta_{i}\right) & =F\left(\hat{\theta}_{i}\right)\left\{W_{i}+\frac{g_{0}}{r}\left(1 / 2+\theta_{i}\right)\left(1-\beta_{R}-\beta_{D}\right)\left[e^{-\gamma r T\left(\hat{\theta}_{i}\right)}-e^{-\gamma r T(\tilde{\theta})}\right]\right. \\
& \left.-\alpha g_{0}\left(1-\epsilon \beta_{R}-\epsilon \beta_{D}\right) e^{-\gamma r T\left(\hat{\theta}_{i}\right)}\right\} \\
& +\int_{x=\hat{\theta}_{i}}^{x=\tilde{\theta}}\left\{W_{i}+\frac{g_{0}}{r}\left(1 / 2+\theta_{i}\right)\left(1-\beta_{R}-\beta_{D}\right)\left[e^{-\gamma r T(x)}-e^{-\gamma r T(\tilde{\theta})}\right]\right. \\
& \left.-(1-\alpha) g_{0}\left(1-\epsilon \beta_{R}-\epsilon \beta_{D}\right) e^{-\gamma r T(x)}\right\} f(x) d x-c\left(\beta_{i}\right) g_{0} e^{-\gamma r T(\tilde{\theta})}
\end{aligned}
$$

where $\tilde{\theta}$ is given by $T(\tilde{\theta})=\tilde{T}$. In addition, as $T^{\prime}(\cdot) \leq 0$, we have $\tilde{\theta} \leq \hat{\theta}_{i}$.

Therefore, differentiating with respect to $\hat{\theta}_{i}$, the first-order condition is (where we drop the $i$ subscript)

$$
\begin{aligned}
\frac{\partial \mathrm{U}}{\partial \hat{\theta}} & =-F(\hat{\theta}) \gamma g_{0} T^{\prime}(\hat{\theta}) e^{-\gamma r T(\hat{\theta})}\left[(1 / 2+\theta)\left(1-\beta_{R}-\beta_{D}\right)-\alpha r\left(1-\epsilon \beta_{R}-\epsilon \beta_{D}\right)\right] \\
& -f(\hat{\theta}) g_{0} e^{-\gamma r T(\hat{\theta}}\left(1-\epsilon \beta_{R}-\epsilon \beta_{D}\right)(2 \alpha-1)=0
\end{aligned}
$$

which becomes, using the definition $\Delta_{\epsilon}\left(\beta_{R}, \beta_{D}\right):=\left(1-\beta_{R}-\beta_{D}\right) /\left(1-\epsilon \beta_{R}-\epsilon \beta_{D}\right)$,

$$
\frac{\partial \mathrm{U}}{\partial \hat{\theta}}=-F(\hat{\theta}) \gamma T^{\prime}(\hat{\theta})\left[(1 / 2+\theta) \Delta_{\epsilon}\left(\beta_{R}, \beta_{D}\right)-\alpha r\right]-f(\hat{\theta})(2 \alpha-1)=0 .
$$

Finally, as $T(\theta)$ is the optimal time of concession for a group with $\operatorname{cost} \theta$, then $\hat{\theta}=\theta$ when $\hat{\theta}$ is chosen optimally. Thus, the FOC (A.6) evaluated at $\hat{\theta}=\theta$ implies the result (11). Yet, substituting $T^{\prime}(\theta)$ evaluated at $\hat{\theta}$ from (11) into (A.5), we obtain

$$
\frac{\partial \mathrm{U}}{\partial \hat{\theta}}=\frac{g_{0} e^{-\gamma r T(\hat{\theta})} f(\hat{\theta})(2 \alpha-1)\left(1-\beta_{R}-\beta_{D}\right)(\theta-\hat{\theta})}{(1 / 2+\hat{\theta}) \Delta_{\epsilon}\left(\beta_{R}, \beta_{D}\right)-\alpha r} .
$$

\footnotetext{
${ }^{31}$ We use $F(\theta)=(1-H[T(\theta)])$
} 
As $(1 / 2+\theta) \Delta_{\epsilon}\left(\beta_{R}, \beta_{D}\right)-\alpha r>0, \forall \theta \in[\underline{\theta} ; \bar{\theta}], \operatorname{sign}\left(\partial_{\hat{\theta}} \mathrm{U}\right)=\operatorname{sign}(\theta-\hat{\theta})$, so that the second order condition is satisfied.

As usual, for any $\theta \in[\underline{\theta} ; \tilde{\theta}]$, the gain from having the opponent drop out is positive. Thus, as long as $f(\bar{\theta})>0$, groups with $\theta<\tilde{\theta}$ will not drop out immediately. Thus, a group with $\theta=\tilde{\theta}$ will drop out immediately, i.e., $T(\tilde{\theta})=\tilde{T}$.

Proof of Corollary 1.

As $f(\theta)$ is uniform over $[\underline{\theta}, \bar{\theta}]$, we have $f(\theta) / F(\theta)=1 /(\theta-\underline{\theta}), \forall \theta \in[\underline{\theta}, \bar{\theta}]$. By $(11)$, as $T(\bar{\theta})=0$ by the Theorem $1, T(\theta)$ can be written as

$$
T(\theta)=\int_{\theta}^{\tilde{\theta}} \frac{(2 \alpha-1) / \gamma}{(s-\underline{\theta})\left[(1 / 2+s) \Delta_{\epsilon}\left(\beta_{R}, \beta_{D}\right)-\alpha r\right]} d s .
$$

Using the method of partial fractions and integrating, (A.7) becomes

$$
T(\theta)=\frac{(2 \alpha-1) / \gamma}{(1 / 2+\theta) \Delta_{\epsilon}\left(\beta_{R}, \beta_{D}\right)-\alpha r} \log \left\{\frac{(\tilde{\theta}-\underline{\theta})\left(\left|(1 / 2+\theta) \Delta_{\epsilon}\left(\beta_{R}, \beta_{D}\right)-\alpha r\right|\right)}{(\theta-\underline{\theta})\left(\left|(1 / 2+\tilde{\theta}) \Delta_{\epsilon}\left(\beta_{R}, \beta_{D}\right)-\alpha r\right|\right)}\right\}
$$

Proof of Proposition 1.

The expected date of stabilization $\left(T^{S E}\right)$ is the minimum of the both groups' optimal drop out times, namely $T^{S E}:=\mathbb{E}\left[\min \left\{T\left(\theta_{R}\right), T\left(\theta_{D}\right)\right\}\right]$. By defining two cases $\left(\theta_{R}<\theta_{D}\right.$ or $\left.\theta_{R} \geq \theta_{D}\right)$, we have $T^{S E}=\mathbb{E}\left[\min \left\{T\left(\theta_{R}\right) ; T\left(\theta_{D}\right)\right\}\left(\mathbf{1}_{\theta_{R}<\theta_{D}}+\mathbf{1}_{\theta_{R}>\theta_{D}}\right)\right]$, where 1 denotes the indicator function. Yet, $T(\cdot)$ is the decreasing function; thus, $T^{S E}=\mathbb{E}\left[T\left(\theta_{D}\right) \mathbf{1}_{\theta_{R}<\theta_{D}}\right]+\mathbb{E}\left[T\left(\theta_{R}\right) \mathbf{1}_{\theta_{R} \geq \theta_{D}}\right]$. As $\theta_{R}$ and $\theta_{D}$ follow the same distribution $F$, we have $T^{S E}=2 \mathbb{E}\left[T\left(\theta_{D}\right) \mathbf{1}_{\theta_{R}<\theta_{D}}\right]$. Let $s \in[\underline{\theta} ; \bar{\theta}]$, as $\theta_{R}$ and $\theta_{D}$ are independent, we have

$$
\begin{aligned}
\mathbb{E}\left[T\left(\theta_{D}\right) \mathbf{1}_{\theta_{R}<\theta_{D}} \mid \theta_{D}=s\right] & =\mathbb{E}\left[T(s) \mathbf{1}_{\theta_{R}<s} \mid \theta_{D}=s\right] \\
& =T(s) \mathbb{P}\left(\theta_{R}<s \mid \theta_{D}=s\right)=T(s) F(s) .
\end{aligned}
$$

Finally, by the expectation of Eq. (A.8), we obtain Eq. (14).

\section{Proof of Corollary 2.}

On the one hand, we can write

$$
\partial_{\Delta} T(\theta)=\int_{\theta}^{\bar{\theta}} \partial_{\Delta}\left\{\frac{(2 \alpha-1) / \gamma}{(z-\underline{\theta})[(1 / 2+z) \Delta-\alpha r]}\right\} d z
$$

where to save notation, $\Delta:=\Delta_{\epsilon}\left(\beta_{R}, \beta_{D}\right)$. Hence,

$$
\partial_{\Delta} T(\theta)=\int_{\theta}^{\bar{\theta}}-\frac{(2 \alpha-1)(1 / 2+z) / \gamma}{(z-\underline{\theta})[(1 / 2+z) \Delta-\alpha r]^{2}} d z
$$

In addition, as $s \in[\theta ; \bar{\theta}]$, we establish the following inequality:

$$
\partial_{\Delta} T(\theta) \leq-\frac{(2 \alpha-1)(1 / 2+\theta) / \gamma}{(\bar{\theta}-\underline{\theta})[(1 / 2+\bar{\theta}) \Delta-\alpha r]^{2}} \leq 0, \forall \theta \in[\underline{\theta} ; \bar{\theta}]
$$


On the other hand, as $\Delta=\left(1-\beta_{R}-\beta_{D}\right) /\left(1-\epsilon \beta_{R}-\epsilon \beta_{D}\right)$, and $\epsilon \leq 1$, we have $\partial \Delta / \partial \beta_{i}=$ $-(1-\epsilon) /\left(1-\epsilon \beta_{R}-\epsilon \beta_{D}\right)^{2} \leq 0$. Consequently, by (A.9), we obtain: $\partial T(\theta) / \partial \beta_{i}=$ $\left(\partial_{\beta_{i}} \Delta\right)\left(\partial_{\Delta} T(\theta)\right) \geq 0, \forall \theta \in[\underline{\theta} ; \bar{\theta}]$. Finally, as $T^{S E}$ is defined by $T^{S E}=\mathbb{E}\left[\min \left\{T\left(\theta_{R}\right), T\left(\theta_{D}\right)\right\}\right]$, we establish that $\partial T^{S E} / \partial \beta_{i} \geq 0, i \in\{D, R\}$.

\section{Appendix B}

Proof of Lemma 1.

Let $i \in\{D, R\}$. Using (19), the function $g$ is defined by

$$
\begin{aligned}
g\left(\hat{\theta}, \beta_{i}\right)=F(\hat{\theta}) & \{\gamma(1 / 2+\theta)[T(\hat{\theta})-T(\tilde{\theta})]+\alpha \epsilon[1-\gamma r T(\hat{\theta})]\} \\
+ & \int_{\hat{\theta}}^{\tilde{\theta}}\{\gamma(1 / 2+\theta)[T(x)-T(\tilde{\theta})]+(1-\alpha) \epsilon[1-\gamma r T(x)]\} f(x) d x .
\end{aligned}
$$

Differentiating with respect to $\hat{\theta}$, we obtain that $\partial g\left(\hat{\theta}, \beta_{i}\right) / \partial \hat{\theta}=\gamma F(\hat{\theta}) T^{\prime}(\hat{\theta})[1 / 2+\theta-\epsilon \alpha r]$. Thus, by (11), we have

$$
\frac{\partial g\left(\hat{\theta}, \beta_{i}\right)}{\partial \hat{\theta}}=-\frac{f(\hat{\theta})(2 \alpha-1)(1 / 2+\theta-\epsilon \alpha r)}{(1 / 2+\theta) \Delta_{\epsilon}\left(\beta_{R}, \beta_{D}\right)-\alpha r} .
$$

By (B.2), with the uniform distribution over $[\underline{\theta} ; \bar{\theta}]$, the function $g$ is given by

$$
g\left(\hat{\theta}, \beta_{i}\right)=\int_{\hat{\theta}}^{\tilde{\theta}} \frac{(2 \alpha-1)(1 / 2+\theta-\epsilon \alpha r)}{(\tilde{\theta}-\underline{\theta})\left[(1 / 2+\theta) \Delta_{\epsilon}\left(\beta_{R}, \beta_{D}\right)-\alpha r\right]} d s+g\left(\tilde{\theta}, \beta_{i}\right),
$$

hence,

$$
g\left(\hat{\theta}, \beta_{i}\right)=\frac{(\tilde{\theta}-\hat{\theta})(2 \alpha-1)(1 / 2+\theta-\epsilon \alpha r)}{(\tilde{\theta}-\underline{\theta})\left[(1 / 2+\theta) \Delta_{\epsilon}\left(\beta_{R}, \beta_{D}\right)-\alpha r\right]}+g\left(\tilde{\theta}, \beta_{i}\right) .
$$

Yet, by $(\mathrm{B} .1)$, the constant $g\left(\tilde{\theta}, \beta_{i}\right)$ is $g\left(\tilde{\theta}, \beta_{i}\right)=\epsilon \alpha(\tilde{\theta}-\underline{\theta})[1-\gamma r T(\tilde{\theta})] /(\bar{\theta}-\underline{\theta})$. Note that as $\tilde{\theta} \leq \bar{\theta}$, the assumption that $\bar{\theta}-\underline{\theta} \geq \underline{s} \geq 1$ ensures that $g\left(\bar{\theta}, \beta_{i}\right) \geq 0$. Thus, we obtain the explicit form of function $g$

$$
g\left(\hat{\theta}, \beta_{i}\right)=\frac{1}{\tilde{\theta}-\underline{\theta}}\left\{\frac{(\tilde{\theta}-\hat{\theta})(2 \alpha-1)(1 / 2+\theta-\epsilon \alpha r)}{(1 / 2+\theta) \Delta_{\epsilon}\left(\beta_{R}, \beta_{D}\right)-\alpha r}+\rho_{\epsilon}(\tilde{\theta})\right\},
$$

where $\rho_{\epsilon}(\tilde{\theta}):=\epsilon \alpha(\tilde{\theta}-\underline{\theta})[1-\gamma r T(\tilde{\theta})]$.

Proof of Proposition 3.

The optimal condition $(21)$ can be rewritten by the implicit function $\varphi:[\underline{\theta} ; \bar{\theta}] \times[0 ; 1 / 2] \rightarrow$ $\mathbb{R}^{*}$. Therefore, (21) becomes

$$
\varphi\left(\theta, \beta_{i}\right):=\left[\frac{\bar{\theta}-\theta}{\bar{\theta}-\underline{\theta}}\right] \frac{2 \alpha-1}{\Delta_{\epsilon}\left(\beta_{R}, \beta_{D}\right)}-c^{\prime}\left(\beta_{i}\right)+\epsilon \alpha=0 .
$$


Yet, anticipating the symmetric equilibrium, we denote the symmetric level of concession by $\beta$, i.e., $\beta_{R}=\beta_{D}=: \beta$. Therefore, as $\Delta_{\epsilon}\left(\beta_{R}, \beta_{D}\right)=(1-2 \epsilon \beta) /(1-2 \beta)$, and using the quadratic function cost $\left(c^{\prime}(\beta)=2 \beta\right),($ B.3) becomes

$$
\varphi(\theta, \beta)=\frac{F(\theta)(2 \alpha-1)(1-2 \epsilon \beta)}{1-2 \beta}-2 \beta+\epsilon \alpha=0 .
$$

Differentiating with respect to $\beta$, we obtain $\partial_{\beta} \varphi(\theta, \beta)=2[1-F(\theta)(2 \alpha-1)(1-\epsilon) /(1-$ $\left.2 \beta)^{2}\right]$. Hence, $\partial_{\beta} \varphi(\theta, \beta) \geq 0 \Leftrightarrow \beta \geq X(\theta):=\{1-\rho(\theta)\} / 2$, where

$$
\rho(\theta):=\sqrt{F(\theta)(2 \alpha-1)(1-\epsilon)} .
$$

First, $\varphi(\theta, \cdot) \in C^{1}([0,1 / 2[)$, and $\varphi(\theta, \cdot)$ increases on $[X(\theta) ; 1 / 2[$ and decreases on $[0 ; X(\theta)]$, as result i. of Lemma 2 implies that $X(\theta) \in[0 ; 1 / 2], \forall \theta \in[\bar{\theta} ; \underline{\theta}]$. Second, if $\alpha \leq \bar{\alpha}_{\epsilon}$, by ii., $\varphi(\cdot, X(\cdot)) \leq 0$, and by (B.4), we have $\varphi(\cdot, \beta) \rightarrow+\infty$ when $\beta \rightarrow 1 / 2$. Thus, by iii. and according to the Intermediate Value Theorem, there are $\bar{\beta}(\cdot) \in[X(\cdot) ; 1 / 2[$ and $\beta(\cdot) \in[0 ; X(\cdot)]$, such that $\varphi(\cdot, \bar{\beta}(\cdot))=0$ and $\varphi(\cdot, \beta(\cdot))=0$.

\section{Lemma 2.}

$$
\begin{aligned}
\text { i. } & 0 \leq X(\cdot) \leq 1 / 2 . \\
\text { ii. } & \forall \epsilon \in[0,1], \exists \bar{\alpha}_{\epsilon} \in[1 / 2,1], \forall \alpha \in\left[1 / 2, \bar{\alpha}_{\epsilon}\right]: \varphi(\theta, X(\theta)) \leq 0, \forall \theta \in[\underline{\theta} ; \bar{\theta}] . \\
\text { iii. } & \varphi(\cdot, 0)>0 .
\end{aligned}
$$

Proof of Lemma 2.

Proof i. As $0 \leq 2 \alpha-1 \leq 1,0 \leq \epsilon \leq 1$ and $0 \leq F(\theta) \leq 1, \forall \theta \in[\underline{\theta} ; \bar{\theta}]$, by (B.5), we have $0 \leq \rho(\cdot) \leq 1$, namely $0 \leq X(\cdot) \leq 1 / 2$.

Proof ii. By (B.4), we can write

$$
s(1-2 \beta) \varphi(\theta, \beta)=(\bar{\theta}-\theta)(2 \alpha-1)(1-2 \epsilon \beta)-2 \beta s(1-2 \beta)+\epsilon \alpha(1-2 \beta),
$$

where $s:=\bar{\theta}-\underline{\theta}$. Evaluated at $\beta=X(\theta):=\{1-\rho(\theta)\} / 2$, we have $(1-2 \beta)=\rho(\theta)$; hence, (where we drop the argument of the function $\rho(\cdot)=\rho$ )

$$
\begin{aligned}
& s(1-2 \beta) \varphi(\theta, X(\theta))=(\bar{\theta}-\theta)(2 \alpha-1)(1-\epsilon+\epsilon \rho)-s \rho(1-\rho)+\epsilon \rho \alpha . \\
& =(\bar{\theta}-\theta)(2 \alpha-1)(1-\epsilon)+\epsilon \rho[(\bar{\theta}-\theta)(2 \alpha-1)+\alpha]-s \rho(1-\rho) .
\end{aligned}
$$

Yet, by (B.5), $(\bar{\theta}-\theta)(2 \alpha-1)(1-\epsilon)=s \rho^{2}$. By substituting in (B.6), we establish

$$
\varphi(\theta, X(\theta)) \leq 0 \Leftrightarrow \xi_{\epsilon}(\alpha):=2 s \rho-s+s \epsilon F(\theta)(2 \alpha-1)+\alpha \epsilon \leq 0 .
$$

Let $\epsilon \in[0,1]$. First, by (B.5), we have $\xi_{\epsilon} \in C^{1}([1 / 2,1])$, and $\xi_{\epsilon}$ increases on $[1 / 2,1]$. Second, $\xi_{\epsilon}(1 / 2)=\alpha \epsilon-s \leq 0$, as by assumption, $\alpha \epsilon \leq 1 \leq s<s$. Third, $\xi_{\epsilon}(1)=$ $2 s \sqrt{F(\theta)(1-\epsilon)}-s+s \epsilon F(\theta)+\epsilon$. Hence, $\epsilon-s \leq \xi_{\epsilon}(1) \leq 2 s \sqrt{1-\epsilon}-s+\epsilon(s+1)$. Finally, according to the Intermediate Value Theorem, for each $\epsilon \in[0,1]$, there is a critical level $\bar{\alpha}_{\epsilon} \in[1 / 2,1]$, such that if $\alpha \leq \bar{\alpha}_{\epsilon}, \varphi(\cdot, X(\cdot)) \leq 0$.

Proof iii. By (B.4), $\varphi(\theta, \beta)$ evaluated at $\beta=0$ is: $\varphi(\theta, 0)=\epsilon \alpha+(\bar{\theta}-\theta)(2 \alpha-1) / s \geq$ $0, \forall \theta \in[\underline{\theta}, \bar{\theta}]$. 
Proof of Theorem 2.

The optimization program is defined by $\max _{(\beta, \hat{\theta}) \in[0 ; 1 / 2[\times[\underline{\theta}, \bar{\theta}]} \mathrm{U}(\beta, \hat{\theta})$. According to Proposition 3, first, if $\alpha>\bar{\alpha}_{\epsilon}$, there are no critical points. By (B.4), the maximum of the utility function is the upper limit, namely $\beta^{*}(\theta)=1 / 2$. Second, if $\alpha \leq \bar{\alpha}_{\epsilon}$, there are two critical points: $\underline{\beta}(\theta)$ and $\bar{\beta}(\theta), \forall \theta \in[\underline{\theta}, \bar{\theta}]$.

Next, by considering $\alpha \leq \bar{\alpha}_{\epsilon}$, we show that the Hessian matrix, denoted by $\mathbf{H}(\beta, \theta)$, is negative definite in $(\beta(\theta), \theta), \forall \theta \in[\underline{\theta}, \bar{\theta}]$. We begin by determining the components of the Hessian matrix when $r \approx 0$ and $\tilde{T} \approx 0$.

First, as $c^{\prime \prime}(\beta)=-2$, by $(18)$, we have

$$
\frac{\partial^{2}}{\partial \beta^{2}} \mathrm{U}(\beta, \theta)=-c^{\prime \prime}(\beta) g_{0}=-2 g_{0}<0 .
$$

Second, using (B.1) and (B.2), the mixed-derivative is simply

$$
\left.\frac{\partial^{2}}{\partial \beta \partial \hat{\theta}} \mathrm{U}(\beta, \theta)\right|_{\hat{\theta}=\theta}=g_{0} \frac{\partial}{\partial \theta} g(\beta, \theta)=-g_{0} \frac{f(\theta)(2 \alpha-1)(1-2 \epsilon \beta)}{1-2 \beta}<0 .
$$

Finally, by (A.6), $\partial^{2} \mathrm{U} / \partial \hat{\theta}^{2}=-g_{0} f(\hat{\theta})(2 \alpha-1)(1-2 \epsilon \beta) /(1 / 2+\theta)(1 / 2+\hat{\theta})^{2}$. Hence, as $\hat{\theta}=\theta$ when $\hat{\theta}$ is chosen optimally, we obtain

$$
\left.\frac{\partial^{2}}{\partial \hat{\theta}^{2}} \mathrm{U}(\beta, \theta)\right|_{\hat{\theta}=\theta}=-g_{0} \frac{f(\theta)(2 \alpha-1)(1-2 \epsilon \beta)}{1 / 2+\theta}<0 .
$$

Thus, by (B.7) and (B.9), it is clear that $\operatorname{tr}(\mathbf{H}(\beta, \theta))<0, \forall(\beta, \theta) \in[0,1 / 2[\times[\underline{\theta}, \bar{\theta}]$.

Now, to determine the sign of the determinant of the Hessian matrix, we define the function $v:[0,1 / 2[\times[\underline{\theta}, \bar{\theta}] \rightarrow \mathbb{R}$ by $v(\beta, \theta):=\operatorname{det}(\mathbf{H}(\beta, \theta))$. Using (B.7), (B.8), and (B.9), the function $v$ is given by

$$
v(\beta, \theta)=2 g_{0}^{2} \frac{f(\theta)(2 \alpha-1)(1-\epsilon \beta)}{1 / 2+\theta}-g_{0}^{2} \frac{f(\theta)^{2}(2 \alpha-1)^{2}(1-2 \epsilon \beta)^{2}}{(1-2 \beta)^{2}} .
$$

Hence, $\operatorname{det}(\mathbf{H}(\beta, \theta))>0 \Leftrightarrow v(\beta, \theta)>0 \Leftrightarrow \Upsilon>0$, where

$$
\Upsilon(\beta, \theta):=\frac{2}{1 / 2+\theta}-\frac{f(\theta)(2 \alpha-1)(1-2 \epsilon \beta)}{(1-2 \beta)^{2}} .
$$

On the one hand, we have $\Upsilon \in C^{1}\left(\left[0,1 / 2[\times[\underline{\theta}, \bar{\theta}])\right.\right.$, and $\lim _{\beta \rightarrow 1 / 2} \Upsilon(\beta, \theta)=-\infty, \forall \theta \in$ $[\underline{\theta}, \bar{\theta}]$. On the other hand, $\Upsilon(\cdot, \theta)$ decreases on $[0,1 / 2[$, as

$$
\frac{\partial}{\partial \beta} \Upsilon(\beta, \theta)=-\frac{2 f(\theta)(2 \alpha-1)[(1-\epsilon)+(1-2 \epsilon \beta)]}{(1-2 \beta)^{3}} \leq 0, \forall(\beta, \theta) \in[0,1 / 2[\times[\underline{\theta}, \bar{\theta}] .
$$

In addition, $\Upsilon(0, \beta)>0 \Leftrightarrow 2>(1 / 2+\theta) f(\theta)(2 \alpha-1)$. Consequently, there is an upper limit $\bar{\theta}^{*}$, which implies that $\Upsilon(0, \beta)>0$. For example, as $f(\theta) \leq \underline{s} \leq 1$ and $2 \alpha-1 \leq 1$, a sufficient condition is that $1 / 2+\bar{\theta}<2$, namely $\bar{\theta}^{*}=3 / 2$. Finally, if $\bar{\theta}<\bar{\theta}^{*}$, according to the Intermediate Value Theorem, there is $\check{\beta}(\theta) \in[0,1 / 2[$, such that $\Upsilon(\beta, \theta)>0$, $\forall \beta \in[0, \check{\beta}(\theta)[$ and $\Upsilon(\beta, \theta) \leq 0, \forall \beta \in[\check{\beta}(\theta), 1 / 2[$. Therefore, the determinant of the Hessian matrix is positive when $\beta \leq \check{\beta}(\theta)$. 
Moreover, Lemma 3 shows that $\beta(\theta)<\check{\beta}(\theta)$. Thus, as $\operatorname{tr}(\mathbf{H}(\beta, \theta))<0$, we obtain that $\beta(\theta)$ is a maximum of the utility function $\mathrm{U}$.

Now, let us show that the upper $\operatorname{root} \bar{\beta}(\cdot)$ is a saddle point: $\operatorname{det}(\mathbf{H}(\bar{\beta}(\theta)), \theta)<0$, namely $\Upsilon(\bar{\beta}(\theta), \theta)<0$. To this end, we adopt a reductio ad absurdum by supposing that $\check{\beta}(\theta)>\bar{\beta}(\theta)$. First, $\Upsilon(\cdot, \theta) \geq 0$ on $[0, \check{\beta}(\theta)[$; thus, $\mathrm{U}(\cdot, \theta)$ is strictly concave on $[0, \check{\beta}(\theta)[$, as $\operatorname{tr}(\mathbf{H}(\beta, \theta))<0$. Consequently, there is a unique maximum $\beta_{\max }(\theta) \in[0, \breve{\beta}(\theta)[$. In addition, according to Lemma $3, \beta_{\max }(\theta)=\beta(\theta)$. Second, if $\check{\beta}(\theta)>\bar{\beta}(\theta)$, we have $\operatorname{det}(\mathbf{H}(\bar{\beta}(\theta), \theta))>0$, and thus, $\bar{\beta}(\theta)$ is a maximum of the utility function. However, as the maximum is unique on $\left[0, \check{\beta}(\theta)\left[\right.\right.$, we obtain a contradiction: $\beta_{\max }(\theta)=\beta(\theta)<\bar{\beta}(\theta)=$ $\beta_{\max }(\theta)$. Thus, $\bar{\beta}(\theta)>\check{\beta}(\theta)$, namely $\bar{\beta}(\theta)$ is a saddle point.

Ultimately, there are at most two critical points, if $\bar{\theta}<\bar{\theta}^{*}$ and, $\alpha<\bar{\alpha}_{\epsilon}^{*}, \underline{\beta}(\theta)$ is the unique maximum of the utility function.

Lemma 3. There are upper limits $\bar{\theta}^{*}$ and $\bar{\alpha}_{\epsilon}^{*}$, such that $\operatorname{det}(\mathbf{H}(\underline{\beta}(\cdot), \cdot))>0$.

We prove Lemma 3 in two steps. The first step establishes that $\beta(\cdot)<1 / 4$, while the second step proves that $\Upsilon(1 / 4, \cdot)>0$, i.e., $\operatorname{det}(\mathbf{H}(1 / 4, \cdot))>0$.

Step 1. By Lemma $4, \underline{\beta}(\theta)$ is increasing with $\epsilon$. Thus, $\underline{\beta}(\theta) \leq\left.\underline{\beta}(\theta)\right|_{\epsilon=1}=: \underline{\hat{\beta}}(\theta)$, $\forall \theta \in[\underline{\theta}, \bar{\theta}]$. Using (B.4), when $\epsilon=1$, only one level of concession respects the FOC, namely $\hat{\beta}(\theta)=[F(\theta)(2 \alpha-1)+\epsilon \alpha] / 2$. Therefore, $\hat{\beta}(\theta) \leq 1 / 4 \Leftrightarrow \alpha \leq[1+F(\theta)] /[2 F(\theta)+$ $\epsilon] \leq 3 / 2[2+\epsilon]=: \tilde{\alpha}_{\epsilon}$. Consequently, if $\alpha \leq \tilde{\alpha}_{\epsilon}, \beta(\bar{\cdot}) \leq 1 / 4$.

Step 2. First, by (B.10), we can write $\bar{\Upsilon}(1 / 4, \theta)>0 \Leftrightarrow 1>2(1-\epsilon / 2)(2 \alpha-$ 1) $f(\theta)(1 / 2+\theta) \Leftrightarrow s>(2-\epsilon)(2 \alpha-1)(1 / 2+\theta)$, where $s:=\bar{\theta}-\underline{\theta} \geq \underline{s}$. Yet, if $\theta \leq \bar{\theta}^{*}$, we have $1 / 2+\theta \leq 2, \forall \theta \in[\underline{\theta}, \bar{\theta}]$. Thus, we obtain $\alpha<\hat{\alpha}_{\epsilon} \Leftrightarrow(2 \alpha-1)(2-\epsilon)<1 / 2 \Rightarrow \Upsilon(1 / 4, \theta)>0$, where $\hat{\alpha}_{\epsilon}:=[5-2 \epsilon] / 4[2-\epsilon]$. Finally, we note that $\bar{\alpha}_{\epsilon}^{*}:=\min \left\{\hat{\alpha}_{\epsilon}, \tilde{\alpha}_{\epsilon}, \bar{\alpha}_{\epsilon}\right\}$.

Consequently, if $\alpha<\bar{\alpha}_{\epsilon}^{*}$, on the one hand, $\Upsilon(\cdot, \theta)$ is monotonically decreasing on $[0,1 / 2[$; on the other hand, $\beta(\theta) \leq 1 / 4$ and $\Upsilon(1 / 4, \theta)>0$. Thus, we obtain that $\Upsilon(\beta(\theta), \theta)>0$, namely $\operatorname{det}(\mathbf{H}(\bar{\beta}(\theta), \theta))>0$.

Lemma 4. Each level of concession that respects the FOC (B.4) rises with $\epsilon$.

Proof. First, $\varphi$ is linear in $\epsilon$, as $\partial_{\epsilon} \varphi(\theta, \beta)=\alpha-2 \beta(2 \alpha-1) F(\theta) /(1-2 \beta)$. Second, as $F(\theta)$ decreases with $\theta, \partial_{\epsilon} \varphi$ is an increasing and continuous function in $\theta$. Furthermore, $\left.\partial_{\epsilon} \varphi\right|_{\theta=\bar{\theta}}=\alpha>0$, and $\left.\partial_{\epsilon} \varphi\right|_{\theta=\underline{\theta}}=-2 \beta(2 \alpha-1) /(1-2 \beta)+\alpha \geq 0$. As $\beta$ is defined by the FOC (B.4), when $\epsilon=1$, we can establish that $(2 \alpha-1) /(1-2 \beta)=2 \beta$. In this way, we have $\left.\partial_{\epsilon} \varphi\right|_{\theta=\underline{\theta}}=-2 \beta(2 \alpha-1) /(1-2 \beta)+\alpha=-4 \beta^{2}+\alpha \geq 0$, as $\beta \leq \alpha \epsilon / 2$ and $-4(\alpha \epsilon / 2)^{2}+\alpha=\alpha\left[1-\alpha \epsilon^{2}\right] \geq 0$.

\section{Appendix C: Proof of Proposition 6}

Using Eqs. (6) to (9), and by (24), in symmetric equilibrium (i.e., $\beta_{R}=\beta_{D}=$ : $\beta$ ), when $\tilde{T} \approx 0$, the social welfare function $L$ evaluated at $(T(\theta), \beta)$ is

$$
\begin{aligned}
L(T(\theta), \beta)=-\gamma g_{0}(1-2 \beta)(1 / 2+\theta) \int_{0}^{T(\theta)} e^{(1-\gamma) r s} e^{-r s} d s & \\
& -\gamma g_{0}(1-2 \beta) \frac{\beta^{2}}{2}+\Delta V(\beta) e^{-r T}
\end{aligned}
$$


where $\Delta V(\beta):=-g_{0}(1-2 \epsilon \beta)$. Thus, when $r \approx 0$, (C.1) becomes

$$
L(T(\theta), \beta)=-\gamma g_{0} T(\theta)(1-2 \beta)(1 / 2+\theta)-\gamma g_{0}(1-2 \beta) \frac{\beta^{2}}{2}-g_{0}(1-2 \epsilon \beta) .
$$

Yet, by (13), we obtain

$$
T(\theta)=\frac{(2 \alpha-1)(1-2 \epsilon \beta)}{(1 / 2+\theta)(1-2 \beta) \gamma} \log \left(X_{\theta}\right), \text { where } X_{\theta}:=\frac{(\bar{\theta}-\underline{\theta})(1 / 2+\theta)}{(\theta-\underline{\theta})(1 / 2+\bar{\theta})} .
$$

By substituting (C.3) into (C.2), we have $L(\theta, \beta)=-g_{0}(2 \alpha-1)(1-2 \epsilon \beta) \log \left(X_{\theta}\right)-\frac{\gamma}{2} g_{0}(1-$ $2 \beta) \beta^{2}-g_{0}(1-2 \epsilon \beta)$. We introduce the function $\zeta(\cdot)$ defined by $\zeta(\beta):=-L(T(\theta), \beta) / g_{0}$. Therefore, $\zeta(0)=(2 \alpha-1) \log \left(X_{\theta}\right) \geq 0$ and $\zeta(1 / 2)=(2 \alpha-1)(1-\epsilon) \log \left(X_{\theta}\right)+(1-\epsilon) \leq \zeta(0)$. In addition, $\zeta^{\prime}(\beta) \geq 0 \Leftrightarrow-3 \gamma \beta^{2}+\gamma \beta-2 \epsilon\left[1+(2 \alpha-1) \log \left(X_{\theta}\right)\right] \geq 0$. Therefore, the discriminant $\Delta$ is given by $\Delta=\gamma\left[\gamma-24 \epsilon\left(1+(2 \alpha-1) \log \left(X_{\theta}\right)\right)\right]$. As $X_{\theta} \geq 1$, we have $\Delta \leq 0$ if $\gamma / 24:=\epsilon_{0} \leq \epsilon$. Consequently, when $\epsilon_{0} \leq \epsilon$, as $\max L=\min \zeta$, and as $\zeta$ is a continuously decreasing function, $\beta^{S W}:=1 / 2=\operatorname{argmax}_{\beta \in[0,1 / 2]} L(T(\cdot), \beta)$. Finally, by (26), as the density's support is finite, we have $\operatorname{ESW}^{\prime}(\beta)=2 \int_{\underline{\theta}}^{\bar{\theta}} \partial_{\beta} L(T(\theta), \beta) F(\theta) f(\theta) d \theta$. Thus, $1 / 2=\operatorname{argmax}_{\beta \in[0,1 / 2]} L(T(\cdot), \beta)=\operatorname{argmax}_{[0,1 / 2]} \operatorname{ESW}(\bar{\beta})$. 